\title{
Multisource energy conversion modes in minimally altered plants with soft epicuticular coatings
}

Fabian Meder ( $\sim$ fabian.meder@iit.it )

Istituto Italiano di Tecnologia

Alessio Mondini

Istituto Italiano di Tecnologia

Francesco Visentin

Istituto Italiano di Tecnologia

Giorgio Zini

Istituto Italiano di Tecnologia

Marco Crepaldi

Istituto Italiano di Tecnologia

Barbara Mazzolai

Istituto Italiano di Tecnologia https://orcid.org/0000-0003-0722-8350

\section{Article}

Keywords: minimally altered plants, leaf epicuticular region, transparent elastomeric coating, multisource energy conversion

Posted Date: April 14th, 2021

DOI: https://doi.org/10.21203/rs.3.rs-389383/v1

License: (c) (i) This work is licensed under a Creative Commons Attribution 4.0 International License.

Read Full License 
1 Multisource energy conversion modes in minimally altered plants with soft epicuticular coatings

3

Fabian Meder ${ }^{1 *}$, Alessio Mondini ${ }^{1}$, Francesco Visentin ${ }^{1}$, Giorgio Zini ${ }^{2}$, Marco Crepaldi ${ }^{2}$, Barbara Mazzolai $^{{ }^{*}}$

1 Bioinspired Soft Robotics Laboratory, Istituto Italiano di Tecnologia, Pontedera, Italy

2 Electronic Design Laboratory, Istituto Italiano di Tecnologia, Genova, Italy

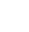

Living plants have recently been exploited for unusual tasks such as energy conversion ${ }^{1-6}$ and environmental sensing. ${ }^{7-12}$ Yet, using plants as small-scale autonomous energy sources ${ }^{1-5}$ was obstructed by insufficient power outputs for steadily driving even low-power electronics. Moreover, multicable and -electrode installations on the plants made a realization challenging. Here, we show that plants, by a minimal modification of the leaf epicuticular region and by exploiting their intrinsic circuitry, can be transformed into cable-free, fully plant-enabled integrated systems for multisource energy conversion. In detail, leaf contact electrification caused by wind-induced inter-leaf tangency was magnified by a transparent elastomeric coating on one of two interacting leaves for converting wind energy into harvestable electricity. Further, augmentation of the power output is achieved by coupling multi-frequency band radio frequency (RF) energy conversion modes using the same plant as an unmatched Marconi-antenna. In combination, we observed up to $1100 \%$ enhanced energy accumulation respective to single source harvesting and a single plant like ivy could power a commercial sensing platform wirelessly transmitting environmental data. This shows that living plants could autonomously supply application-oriented electronics while maintaining the positive environmental impact ${ }^{13}$ by their intrinsic benefits such as $\mathrm{O}_{2}$ production, $\mathrm{CO}_{2}$ fixation, self-repair, and many more extremely difficult (if at all possible) to realize in artificial harvesters.

Plant-integrated solutions like plant-hybrid sensing platforms $s^{7-12}$, plant-internal electronic circuits ${ }^{14,15}$, and plant-hybrid robotics ${ }^{16}$, as well as living plant-driven energy harvesting ${ }^{1-3}$ using wind ${ }^{5}$, rain drops ${ }^{4}$, the root/soil microbiome ${ }^{17,18}$, and sap components ${ }^{19,20}$ endow great prospects for connecting plants to man-made digitalized technology and eventually derive new, sustainable concepts to fight climate change. Often, substantial modification of specific species is required like installing specific electrodes, integrated systems like artificial leaves, and multiple cables and maintaining certain conditions (e.g., high humidity, assure enzymatic activity etc.) to realize the plant-hybrid energy harvesting. Plants continuously change their morphology by growing at their apical regions and by exchanging leaves. Hence, preserving complex artificial components in plants is a challenging issue and environmentally questionable on a larger scale. Consequently, approaches that require minimal alteration of the biological component by further integration and elimination of external components as best as possible are required. 
Our approach consists in modifying plants with the least possible, micrometer-scale variation while rendering them capable to obtain significant electrical outputs using a combination of wind-induced interleaf touching and plant-antenna-based radiofrequency energy conversion. Fig. 1a gives an overview of the plant's simplified electrical structure consisting of the dielectric and purely polymeric cuticular membrane on the leaf surface and the ion-conductive inner cellular tissue and vascular system. A mechanical contact between the cuticle and another material leads to contact electrification generating surface charges that become electrostatically induced into the tissue as detailed in our previous investigations. ${ }^{1}$ In this work, we describe for the first time how to fully realize and integrate the mechanical energy conversion in the plant using contacts of two leaves. Given by the wellrecognized rules of contact electrification ${ }^{21-23}$, two similar materials $(M 1=M 2)$ such as two cuticles that touch each other would generate insufficient charges for energy harvesting as they naturally consist of structurally similar lipids and waxes ${ }^{24}$ forming a material pair that does not enhance contact electrification. However, by tuning the materials (M1, M2) of the interacting cuticles, higher charging may be achieved and hence we integrated a thin epicuticular dielectric layer of silicone elastomers on the leaf cuticle as one of the best counter materials for efficient contact electrification of plant leaves. ${ }^{1,3}$ Fig. $1 \mathrm{~b}$ illustrates a simplified circuit used to predict the behavior of a coated leaf when transiently touching an uncoated leaf such as during wind fluttering. Fig. 1c shows the voltage amplitude as function of the impedance of the soil $\left(R_{\text {soil }}\right)$ between two nearby plants. During transient mechanical contact, the two leaves generate a corresponding alternating current $(A C)$ of opposite polarity. If $\mathrm{R}_{\text {soil }}$ is lower than a given threshold, the signals compensate each other through the internal plant-soil circuit and cannot be easily harvested. The equivalent occurs, when two leaves on the same plant touch each other as the intrinsic tissue resistance does not provide sufficient separation of the two electrodes (Fig. 1d). However, at sufficiently high $\mathrm{R}_{\text {soil }}\left(>10^{8} \Omega\right)$ the charges generated can be separated and the electricity produced on both leaves can be effectively harvested (Fig. 1c). High $R_{\text {soil }}$ 's can simply be achieved by potting plants in isolating pots (common plastic-based pottery), in dry soil, or for example by maintaining long distances between leaves and roots/soil. Moreover, it is expected that multiple leaf pairs generating signals at various frequencies and amplitudes lead to an overall positive power balance (Extended Fig. 2). 

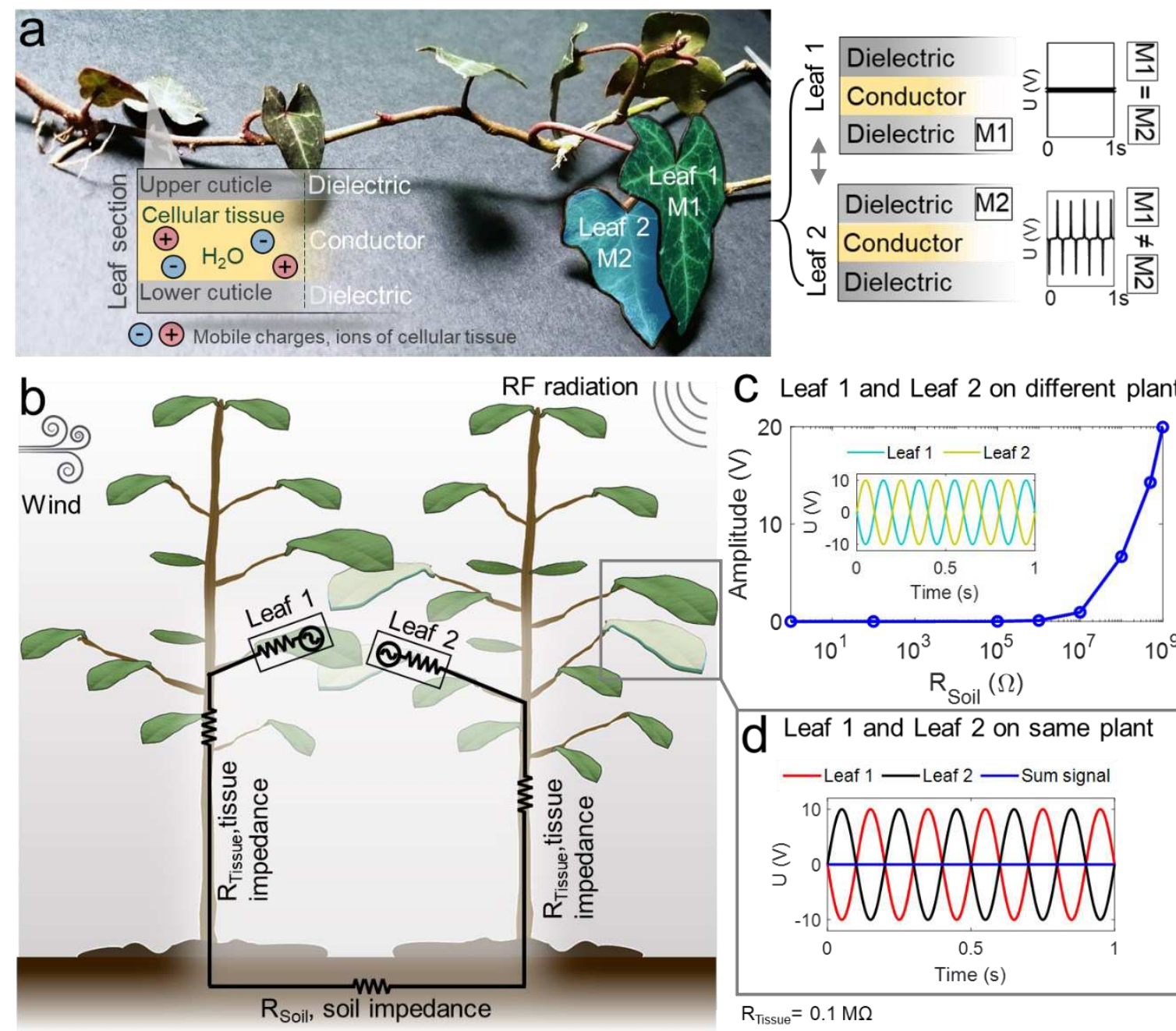

C Leaf 1 and Leaf 2 on different plant

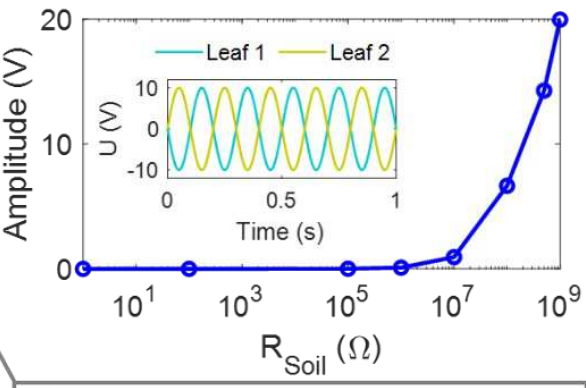

d Leaf 1 and Leaf 2 on same plant

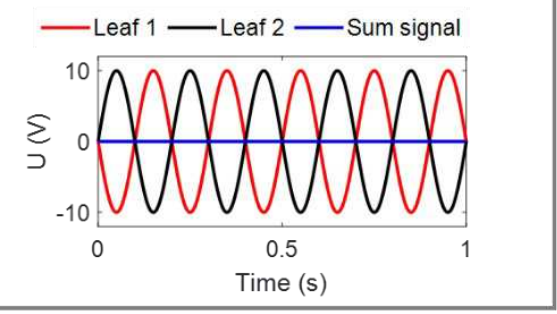

$\mathrm{R}_{\text {Tissue }}=0.1 \mathrm{M} \Omega$

Fig 1. Overview and model of living plant structure-based multisource energy harvesting. a) Inner cellular and vascular tissue are ionic conductors; the cuticle on the plant surface is a dielectric polymeric layer. When a leaf with epicuticular coating comes in contact with an uncoated leaf, contact electrification generates only considerable voltages $\mathrm{U}$ in the tissue if the dielectric material $\mathrm{M} 1$ and $\mathrm{M} 2$ inhere a material pair that specifically enhances contact electrification, typically $M 1 \neq M 2$. b) Illustration of basic circuitry established by the plants in a wind and RF energy harvesting scenario. c) Circuit modelling reveals that during mechanical interaction of two leaves from different plants, voltages in the tissue build up only when $R_{\text {soil }}$ is sufficiently high. $d$ ) Signals of the two leaves cancel out when the leaves are on the same plant, due to too low tissue impedances (typically 0.1-1 M $\Omega$ ).

We then selectively deposited thin epicuticular silicone coatings ( $10 \mathrm{mg} / \mathrm{cm}^{2}, 94 \pm 16 \mu \mathrm{m}$ thick) on model species Ficus macrocarpa (Fig. 2a) on the adaxial surface of leaves with less stomata compared to the abaxial surface (Fig. 2b) to reduce coatings effect on plant transpiration. We analyzed the plant's viability after coating the entire foliage by observing growth in a 1-year-period and by measuring whole-plant level $\mathrm{CO}_{2}$ and $\mathrm{H}_{2} \mathrm{O}$ transpiration rates during day-night cycles (Fig. 2c-e) revealing that transpiration and growth capabilities are maintained and that the epicuticular coating does not seem to affect plant health. This is also supported by the fact that the thin, soft, adaptive, and semipermeable coatings allow high light transmission at wavelength regimes essential for leaf photosynthesis (Fig. 2f). In addition, the coatings on mature leaves (which are fully developed) does 
not give a substantial mechanical obstruction to further plant growth and development (see new leaf and branch development in 1-year-growth-period Fig. 2c).

Fig. $2 \mathrm{~g}$ and $2 \mathrm{~h}$ show the strong increase in the voltage amplitudes at given impact force and frequency, respectively after coating when two leaves of two F. microcarpa touch each other. Signals successfully induced in the inner tissue were measured by a single pin-electrode in the stem at a distance of 15 $\mathrm{cm}$ of the stimulated leaves. Voltage amplitudes up to $25 \mathrm{~V}$, generated by one leaf pair are produced by combination of coated and uncoated leaves ( $c-u$ pair) whereas the contact between uncoateduncoated leaves ( $u$-u pair) show signals in the $\mathrm{mV}$ range (details in Extended Data Fig. 1a-c). The experiment reveals a 450-times increase in the generated potential difference for c-u pairs compared to $\mathrm{u}$-u pairs. The current generated by a single c-u pair reaches an amplitude of $0.75 \mu \mathrm{A}$ (Extended Data Fig. 1d). Fig. 2i shows an arrangement of two plants used to test voltage generation during airflow/wind-excitation. Therein a c-u and a $u-u$ leaf pair were realized at the position where both plants overlap and substantial voltages are obtained expectedly only from c-u pairs (Fig. 2j). Moreover, the output voltage scales with the wind speed bearing a potential for an air-flow sensing capability (Fig. $2 \mathrm{k}$ ). The contact of just two leaves in such a configuration can already charge a $10 \mu \mathrm{F}$ capacitor in windsusceptive manner (Fig. 2l). 

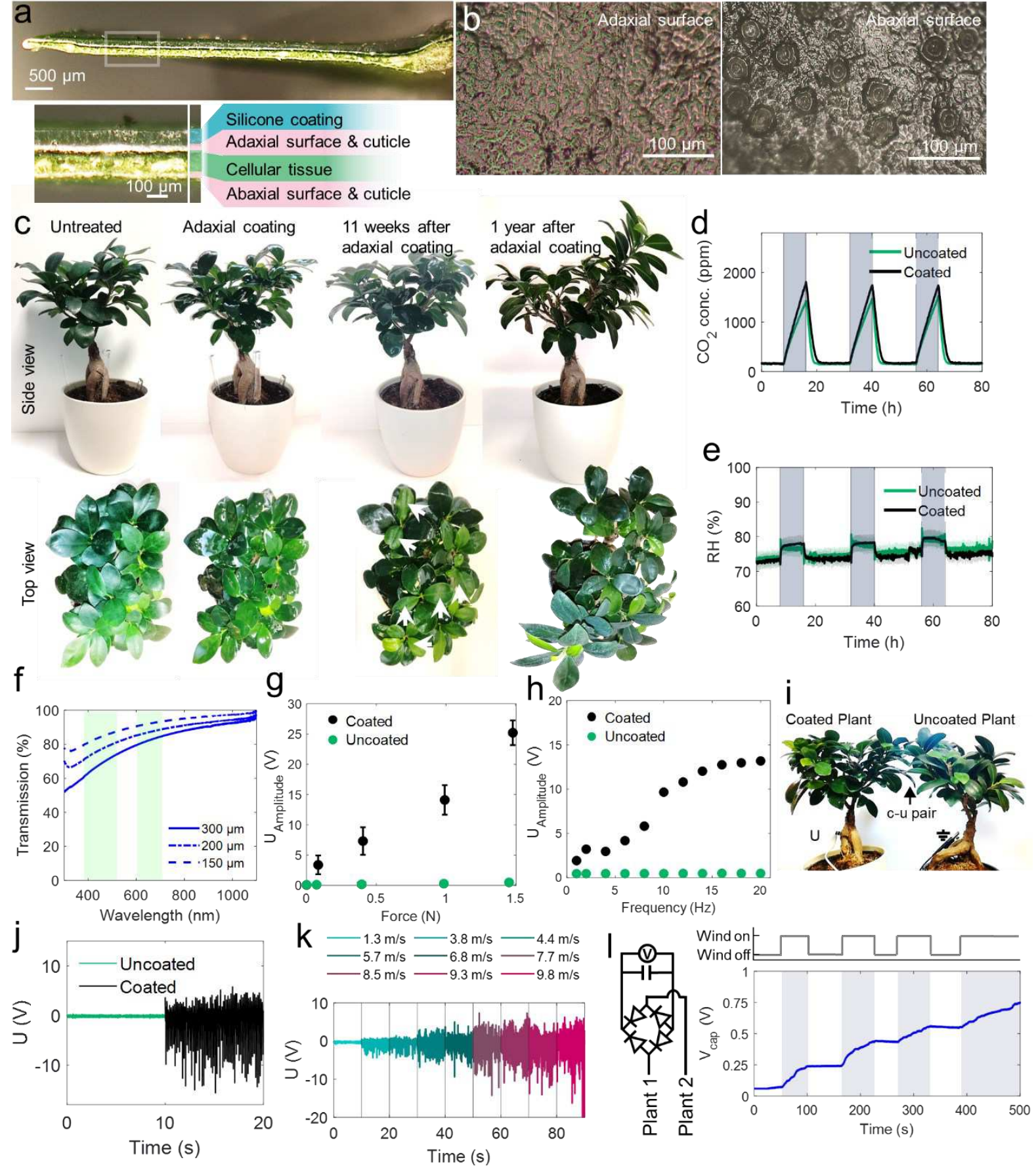

Fig 2. Leaf-epiculticular coating, influence on plant viability, and enhancement of mechanical energy harvesting. a) Cross-section of $F$. microcarpa leaf with $\sim 100 \mu \mathrm{m}$ epicuticular silicone rubber coating on adaxial surface. b) Microscopy images representing stomatal density on adaxial and abaxial leaf surface. c) One-year growth observation of a fully coated $F$. microcarpa. White arrows point to new leaves that developed within 11 weeks after coating growing further into new branches within 1 year. d) and e) $\mathrm{CO}_{2}$ and $\mathrm{H}_{2} \mathrm{O}$ transpiration (in $\mathrm{RH} \%$ ), respectively before and after epicuticular coating. f) Light transmission of epicuticular coatings, green bars highlight photosynthesis relevant wavelengths. $g$ ) and h) Enhancement of voltage generation after epicuticular coating as function of impact force (@10 Hz frequency), and of frequency (@1N impact force), respectively in u-u and c-u leaf pairs. i) Two $F$. 
microcarpa (left, coated, right uncoated) in separate pots, overlapping leaves used for wind energy harvesting. j) Air-flow induced voltage generation of the $u-u$ and $c-u$ F. microcarpa pair. k) Voltage generation as function of windspeed in a c-u F. microcarpa pair. I) c-u F. microcarpa leaf pair-based capacitor charging $(10 \mu \mathrm{F})$ with indicated circuit as function of wind source on-off switching.

For proving that the effect is species-transferable and to analyze a plant species that is especially interesting for urban ecosystems realized by vertical plant growth and greening of buildings ${ }^{25}$, we modified the climber Hedera helix (ivy) with epicuticular coatings on multiple leaves of two intertwining plants to obtain c-u pairs (Fig. 3a) and by coating again the adaxial leaf surfaces with less stomata, Fig. 3b. The generated voltage amplitude of $c$-u pairs scales with the impact force as well as the area reaching now even up to $\sim 50 \mathrm{~V}$ for single leaves (Fig. $3 \mathrm{c}$ and $3 \mathrm{~d}$, respectively with $2 \mathrm{~cm}^{2}$ contact area and $1 \mathrm{~N}$ impact force). The power analysis of the system reveals a peak power at $17 \mu \mathrm{W} / \mathrm{cm}^{2}$ (at $1 \mathrm{~N}$ stimulus and a load resistance of $200 \mathrm{M} \Omega$ ), which are typical values achieved with plant-hybrid systems $\mathrm{s}^{1,5}$ and many common triboelectric and piezoelectric generators ${ }^{26-28}$ in particular at low impact forces. This shows that the combination of the epicuticular coatings and the whole plant as a circuit is competitive despite minimal fabrication effort and can even convert low forces $\leq 1 \mathrm{~N}$ into satisfactory electrical energy - notwithstanding the expectedly relatively low mechanical-to-electrical energy conversion efficiency at non-optimum conditions $\left(5.6^{*} 10^{\wedge}-5 \%\right.$, for the c-u pair). Indeed, the energy harvested from a single c-u pair is sufficient to supply a commercial temperature sensor with wireless transceiver connected to the plant using the circuit in Fig. 3f. The charging curve of the $136 \mu \mathrm{F}$ capacitor driving the sensor during c-u pair excitation $(1 \mathrm{~N}, 30 \mathrm{~Hz})$ is depicted in Fig. $3 \mathrm{~g}$ along with the wirelessly transmitted data and received signal strength.

The whole-plant $H$. helix (Fig. 3h) is also capable of converting wind energy into electricity. Fig. 3i shows the correlation of the voltage signal with the distance variation $\Delta \mathrm{d}$ between two leaves in a c-u leaf pair fluttering at a wind speed of $\sim 8 \mathrm{~m} / \mathrm{s}$ (Video 1 shows the fluttering motions of $\mathrm{c}$-u pairs leading to signal generation in $\mathrm{H}$. helix and F. microcarpa). The data confirms that the transient contact-andrelease events are caused by the leaf oscillations leading to corresponding voltage signals. As analysis showed that the output is force- and contact area-dependent, the system is more efficient, the higher the kinetic energy is that is transferred to the leaf surface instead of being dissipated by mechanical deformation of the leaf and the petiole. Thus, a supporting rigid substrate such as a wall on which the plant climbs (a typical support for $H$. helix, Extended Data Fig. 3a) facilitates that more kinetic energy translates into contact electrification (and not elastic deformation). We analyzed the wind-speeddependent voltage and current signals using a supporting panel (overview and characteristics of different panel materials are given in Extended Data Fig. 3b, 3c). The panel (Fig 3j) holds eight c-u pairs of two $\mathrm{H}$. helix plants. Fig 3k shows that wind-generated voltage and current signals scale with windspeed and reach amplitudes up to $\sim 10 \mathrm{~V}$ and $\sim 1 \mu \mathrm{A}$, and thus $10 \mu \mathrm{W}$ peaks, respectively. Although this is sufficient to drive low-power electronics, the power output of solely mechanical energy conversion can be theoretically upscaled using more leaf-pairs due to the contact area-output relationship and by achieving a more effective c-u contact as function of leaf orientations and support. However, at still air and very low wind speeds, the system would not provide the same energy and other effects occurring outdoor like wetting of the leaf surface (during rain periods) will affect the signal transiently even if it recovers after leaf-drying (see effect of leaf-wetting on mechanical energy conversion, Extended Data Fig. 4). Limitations of a single energy source could be overcome by realizing multiple independent and complementary energy conversion modes in plants for different energy sources. 

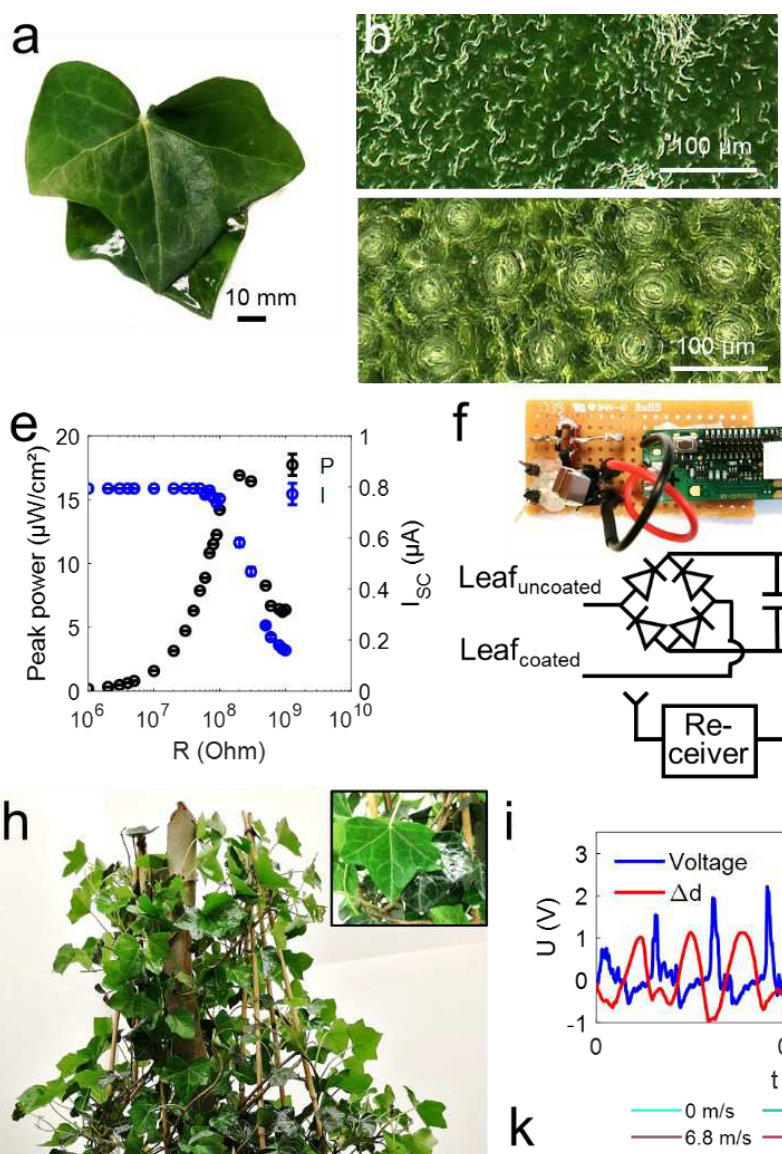

h

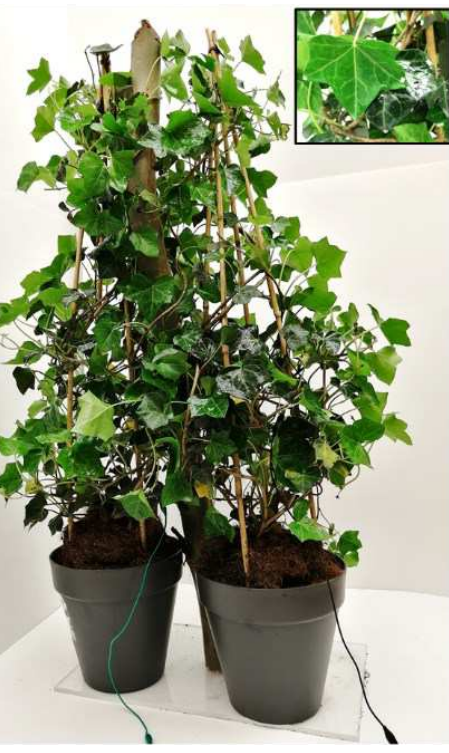

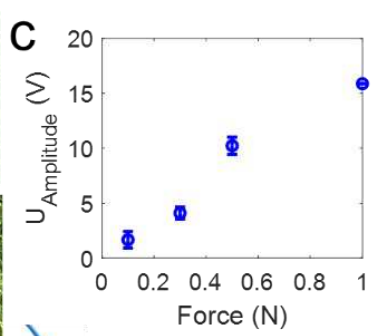
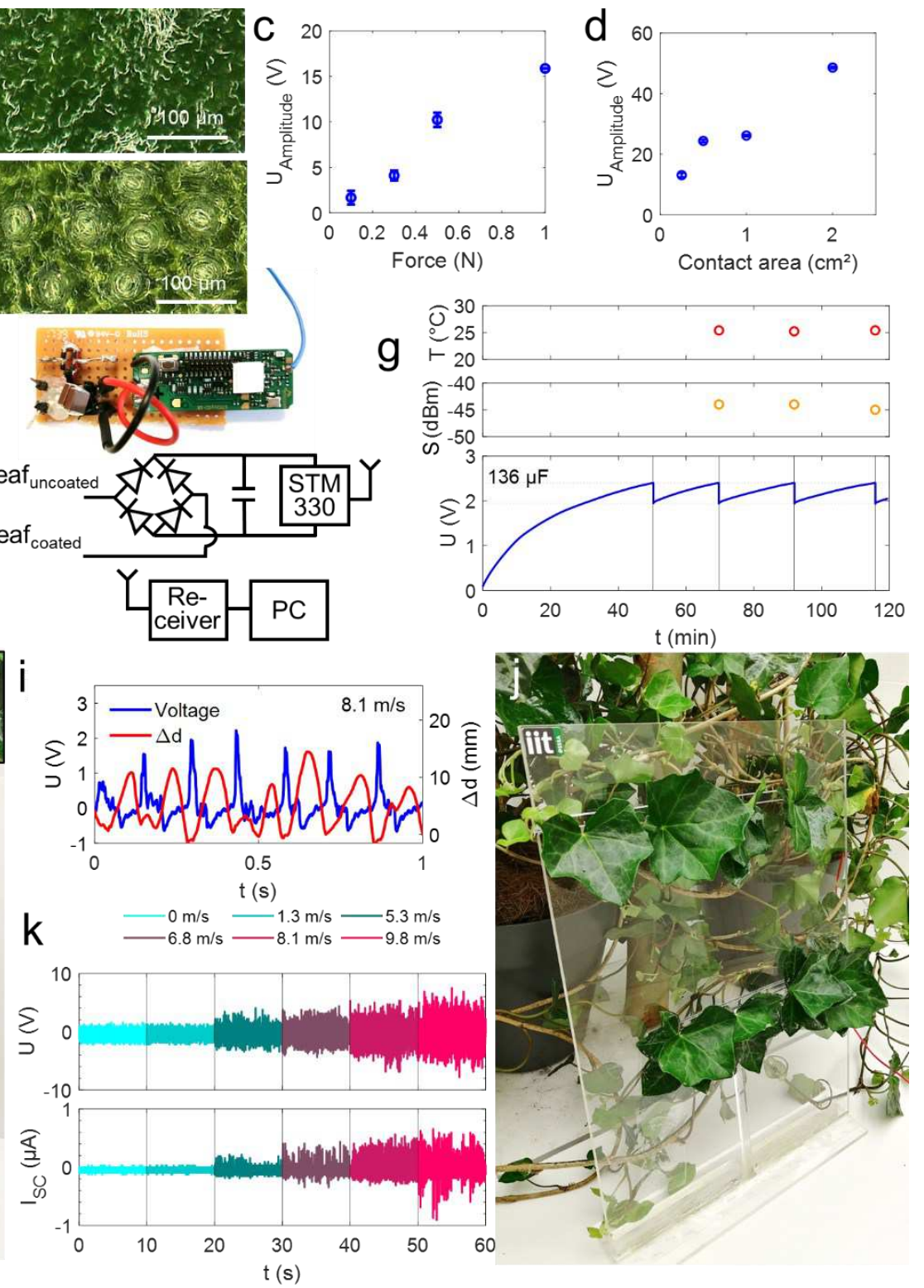

Fig 3. Realization of mechanical energy harvesting in epicuticular coated climber $\boldsymbol{H}$. helix. a) Photograph of a $\mathrm{H}$. helix c-u leaf pair. b) Microscopy images representing stomatal density adaxial on adaxial and abaxial leaf surface. c) and d) Voltage amplitude generated by a $\mathrm{H}$. helix c-u leaf pair as function of impact force (@ contact area $0.25 \mathrm{~cm}^{2}$ ) and contact area (@ 1N impact force), respectively (10 Hz stimulus). e) $\mathrm{H}$. helix c-u leaf pair peak power analysis as function of load of resistance. f) Circuit overview used in g) wirelessly transmitted temperature measurement data packets and signal strength of a c-u leaf pair powered wireless sensor (@1 N, $30 \mathrm{~Hz}$ mechanical stimulation). h) Typical arrangement for $\mathrm{H}$. helix wind energy harvesting in which multiple c-u leaf pairs are realized from two separately potted plants. i) Correlation of voltage signal generated and distance of the two surfaces in a $\mathrm{H}$. helix c-u leaf pair fluttering in air-flow. j) Voltage and short circuit current generated by eight c-u pairs under wind excitation. Unidirectional leaf pairs were realized by fixing two branches of the two H. helix on a support panel as shown in k) for exposure to wind.

172 Indeed, a further opportunity for augmenting the overall power output arises, if the plant structure, a branched conductor with dielectric outer surface, would be suitable for RF energy harvesting and 
plants were previously suggested for radio reception and transmission. ${ }^{29,30}$ We thus analyzed the received spectrum using the $H$. helix as a receiving antenna in an outdoor environment with ambient RF pollution (Fig. 4a). The power spectrum analysis shows that the plant receives signals at multiple frequencies: 100 to $800 \mathrm{kHz}$, low and medium frequency radio communication; at $87-107 \mathrm{MHz}$, ultrahigh frequency FM broadcast radio stations; at $\sim 800 \mathrm{MHz}$, likely related to Global System for Mobile Communications (GSM); 2.1-2.2 GHz range, fourth generation (4G) broadband cellular network showing broad range RF reception. We thus slightly modified the harvesting circuit by introducing an earth connection at the rectifier providing a potential difference so that the plant can act as vertical receiver of a Marconi-antenna (Fig. $4 \mathrm{~b}$ ). Indeed, the charging kinetics of a $68 \mu \mathrm{F}$ capacitor with and without connecting the circuit to two $H$. helix (height $\sim 120 \mathrm{~cm}$ ) suggests that the signals received by the plant can be converted and stored without the need of any further modifications of the plant.

We then exposed the $H$. helix to a fluorescent lighting system acting as a controllable RF source (onoff switching caused a transient peak received by the plant in the $\mathrm{kHz}$ range, likely caused by the ballast emission of the fluorescent lighting system $\left.{ }^{31}\right)$ in a phytochamber $\left(25^{\circ} \mathrm{C}, 40-50 \% \mathrm{RH}\right)$. Characteristics of the RF source in terms of electric field strength and emitted power $(6.9 \pm 2.3 \mathrm{dBm}$ along plant z-axis) are given in Extended Data Fig. $6 \mathrm{a}$ and 6b. Fig. 4c shows the charging kinetics of a $68 \mu \mathrm{F}$ capacitor and the main frequencies received by the plants. The maximum instantaneous power transfer under these conditions were $250 \mathrm{nW}$ at a matching load resistance of 10-30 M $\Omega$ and a maximum current of $300 \mathrm{nA}$ by considering the capacitor as the load. In addition, to exclude that the exposure to light/dark conditions and circuit components such as shielded antenna cables for connecting the plant have an effect, we measured the capacitor charging and frequency spectrum when $H$. helix was fully covered with a lightproof cloth and of the bare circuit with all cables but without plants, respectively. Exposure to darkness did not affect charging and processes related to photosynthetic activity expectedly do not influence the plant-driven charge accumulation from RF energy. The capacitor charging without plant is yet marginal confirming that the plant is the main receiving antenna. Indeed, obstructing ion mobility and conduction by naturally drying the tissue eliminates the charging capability (Extended Data Fig. 5a). The Bode plots of the tissue impedance and phase shift analyzed up to a frequency of $1 \mathrm{MHz}$ show the typical behavior of electrolyte-based conductors (Extended Data Fig. 5b) signifying that tissue ion motion is caused over a large frequency range. Ions for receiving RF signals are also used in ionic liquidand water-based antennas. ${ }^{32}$ Varying the distance of the $H$. helix from the RF source influences the capacitor charging kinetics (Extended Data Fig. 6c) as the power and the field strength (Extended Data Fig. $6 a$ and $6 \mathrm{~b}$ and inset in Fig. 4c) expectedly decrease with the distance from the source. Comparing the emitted power of the RF source and the instantaneous power charging the capacitor $P_{\text {cap,charging }}$ provided by the plant suggests a specific efficiency of $2.2 * 10^{-3} \%$ in this experiment of the plant converting the RF signal into electricity. The harvesting circuit operates at an efficiency of $\sim 1 \%$

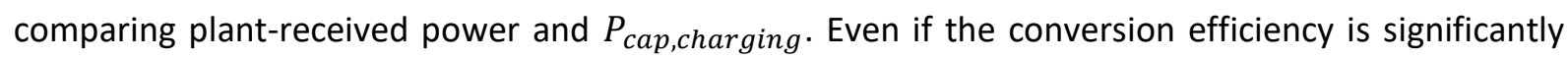
lower than for tuned RF harvesting systems ${ }^{33}$, the simplicity of realization and marginal material consumption in our case rises the overall sustainability. 

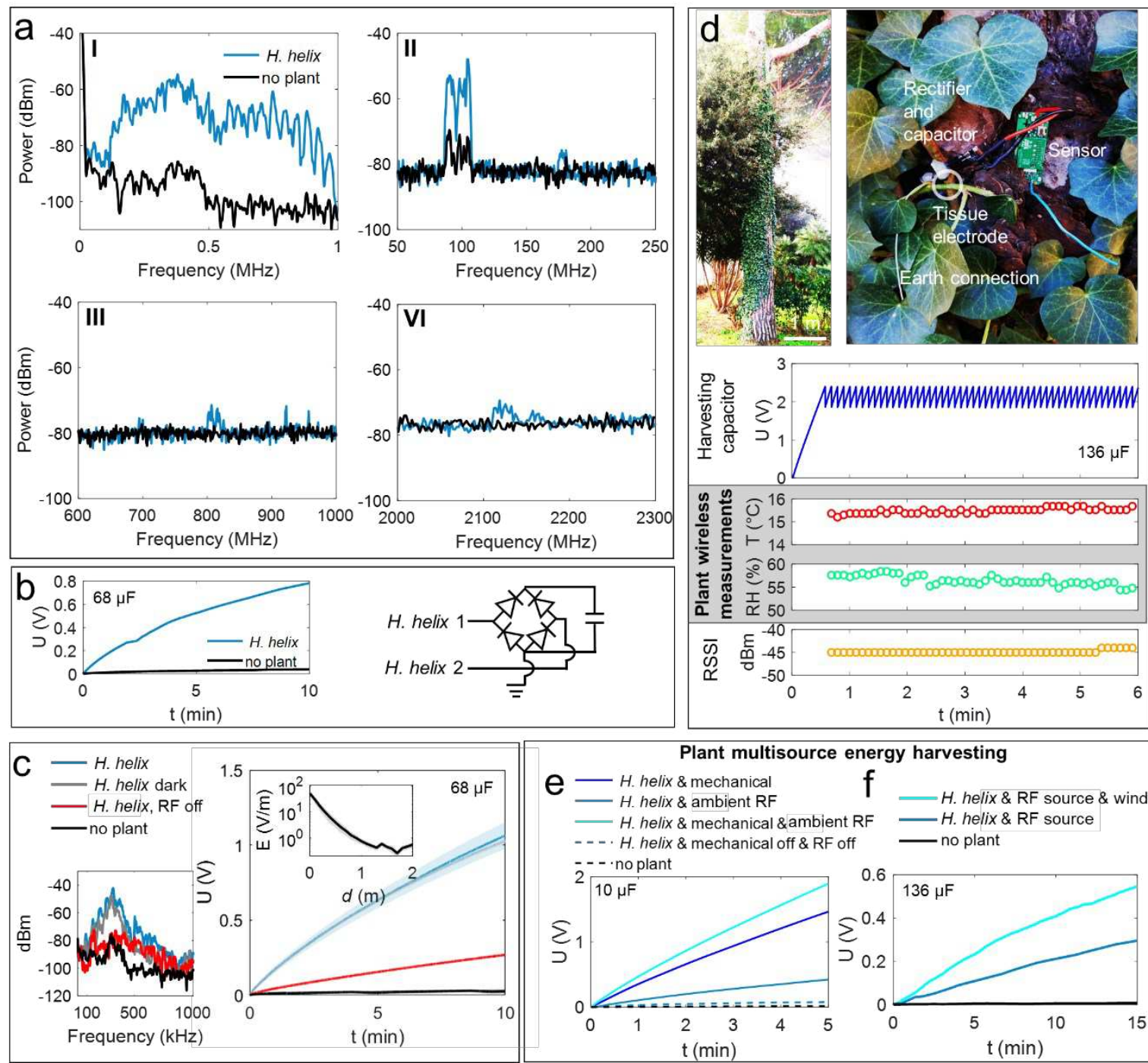

Fig. 4 Plant based RF energy harvesting and boosted multisource wind-RF energy harvesting. a) and b) overview of the frequencies received by an H. helix acting as antenna outdoor (e.g., @100 MHz, center frequency of nearby radio emitter), circuit and charging curve of a $68 \mu \mathrm{F}$ capacitor relative to these signals, respectively indicating potential to transduce RF radiation into electricity. c) Exposure of $H$. helix in dark and light conditions to a switchable RF source resulting in a received main frequency $\sim 400 \mathrm{kHz}$-center when the RF source is on, when off, the peak diminishes. The capacitor charging curves ( $68 \mu \mathrm{F}$ ) show RF-source and plant-dependent energy harvesting by $H$. helix. The inset shows the electric field strength as function of distance from the RF source, energy harvesting was performed in $\sim 1 \mathrm{~m}$ distance, further details in Extended Data Fig. 5. d). Demo of a plant-powered sensing and wireless data packet transmission using a modified commercial sensing system in an outdoor environment with a $\mathrm{H}$. helix growing on a pine tree, charging of a $136 \mu \mathrm{F}$ capacitor powering sensor and transceiver unit. The plant powers a humidity/temperature sensor and wireless data transmission, plant-powered measurements and transmission signal strengths are given. e) Multisource (mechanical and RF) energy harvesting with a $\mathrm{c}-\mathrm{u} \mathrm{H}$. helix pair by selectively adding RF (environmental) or mechanical energy (controlled $1 \mathrm{~N}, 10 \mathrm{~Hz}$ stimulus) sources leads to increasing capacitor charging dynamics. f) Multisource wind and RF plant energy harvesting, wind speed $~ 8.1 \mathrm{~m} / \mathrm{s}, \mathrm{RF}, 400 \mathrm{kHz}$ center frequency, (see spectrum analysis in c)), conversion by $\mathrm{c}-\mathrm{u} \mathrm{H}$. helix pairs as described in Fig. 3 feeding a $136 \mu \mathrm{F}$ capacitor. Combination of RF and wind leads to a $550 \%$-increase in the energy output compared to RF as single source. 
An interesting application scenario is exploiting the plants of urban vegetation for powering batteryfree environmental sensing. We thus modified a commercial sensor and wireless transceiver by the plant-charging circuit shown in Fig. $4 \mathrm{~b}$ as exclusive energy source and connected it to a $\mathrm{H}$. helix growing on a pine tree in the front yard of a multifamily residence in a suburb of Pisa, Italy, (Fig. 4d) using the house's ground connection as potential difference. Fig. $4 \mathrm{~d}$ shows the voltage over the $136 \mu \mathrm{F}$ capacitor powering the system. Indeed, the plant autonomously powers the sensor platform and the wireless transmission telegrams with temperature and humidity data shown in Fig. 4d.

Each measurement requires $\sim 75 \mu \mathrm{C}$ according to the related voltage drop and the average time required to harvest these charges is about 6 seconds in this configuration. The $136 \mu \mathrm{F}$ capacitor driving the sensing unit is only powered when the plant is connected to the circuit with a species-dependent charging behavior (Extended Data Fig. 7a-i). Analysis of the received signals, charging dynamics, and spectrum analyses of the multiple species-received signals are given in Extended Data Fig. 7a-i indicating that different species of existing vegetation are suitable to harvest energy from electromagnetic noise and radiation at frequencies from the super low frequency mains radiation (50 $\mathrm{Hz}$ ) to higher frequencies such as here a peak at $657 \mathrm{kHz}$ related to a MW radio emitter in $8 \mathrm{~km}$ distance. A high contribution of the energy harvested in the urban scenario is due to $50 \mathrm{~Hz}$ mains radiation (99.9\% of energy accumulated and about $0.1 \%$ was related to other ambient RF pollution, Extended Data Fig. 7j) rendering the system in particular suitable for energy harvesting nearby buildings. The average instantaneous power output with the $H$. helix during the outdoor experiments was $6.8 \mu \mathrm{W}$ and $10.5 \mu \mathrm{W}$ using a pine tree, respectively.

We then proved that both energy conversion modes (mechanical and RF) can be simultaneously used. Therefore, we exploited a setup that enables to selectively switch between RF exposure and mechanical excitation. A c-u leaf pair realized in two $H$. helix plants $(30 \mathrm{~cm}$ height) was mechanically stimulated at controlled frequency $(10 \mathrm{~Hz})$ by a linear actuator in a Faraday cage. Ambient RF exposure was controlled by adding/removing the electromagnetic shielding. Fig. 4e shows capacitor charging curves under different conditions. The results confirm that both energy sources can be independently and simultaneously harvested. Moreover, when RF and mechanical stimulation are simultaneously applied, the signals add up leading to faster capacitor charging using the same rectifying circuit. The graph shows that the accumulated sum charges of both sources corresponds to the difference obtained when both sources are used independently. The overall enhancement in the energy accumulated by using the plant to convert the combination of mechanical and ambient RF energy in this experiment corresponds to an 11-times (or 1100\%) increase compared to only RF energy harvesting. Likewise, a strong enhancement was also observed when $H$. helix $(120 \mathrm{~cm})$ was exposed to wind and RF radiation. Fig $4 \mathrm{f}$ shows charging dynamics of a $136 \mu \mathrm{F}$ capacitor by the $H$. helix exposed to $\mathrm{RF}$ emitted by the fluorescent lighting system of the phytochamber and additional air flow stimulating c-u pairs. The data shows an enhancement in the accumulated energy of $550 \%$ compared to RF-only harvesting.

In summary, we have presented a multisource energy harvesting approach by exploiting intrinsic properties of plants. The epicuticular coatings on the leaf surfaces strongly enhance mechanical and wind energy conversion leading to a cable-free plant-based wind generators. In addition, using plant as receiving antenna harvesting multiband RF energy led to up to $1100 \%$ enhancements in the overall energy accumulation. In this configuration, a common $\mathrm{H}$. helix with cuticle coating integrates into a fully flexible battery-free system that can harvest wind and RF energy simultaneously in an easily 
realizable and highly sustainable manner for autonomously powering commercial sensing platforms for environmental monitoring. In comparison with artificial energy harvesters, plants are the most sustainable and eco-friendly approach with excellent overall power balance that enables supplying commercial sensors without great modification of the plant itself.

\section{Methods}

\section{Plant species}

F. macrocarpa (height $\mathrm{h}=25 \mathrm{~cm})$, large $H$. helix $(\mathrm{h}=120 \mathrm{~cm})$, small $H$. helix $(=35 \mathrm{~cm})$ were purchased at a local plant nursery. The plants were kept in a phytochamber controlled at $50-60 \%$ relative humidity $(\mathrm{RH})$, a temperature of $25^{\circ} \mathrm{C}$, and lighting in a 16 hours day and 8 hours night cycle, watered twice per week, and fertilized once per month with a green plant fertilizer. Outdoor experiments with common urban vegetation, i.e., $H$. helix, $P$. pinea, $Y$. elephantipes, and $P$. peltatum were performed during the period of May 2020 to February 2021 in the front yard of a multifamily residence in a suburb of Pisa, Italy. H. helix $(h=\sim 8 \mathrm{~m})$ grew naturally on the stem of a $\sim 15 \mathrm{~m}$ high $P$. pinea tree and $Y$. elephantipes $(\mathrm{h}=2.5 \mathrm{~m})$ grew in a distance of about $4 \mathrm{~m}$ from the $P$. pinea. $P$. peltatum $(\mathrm{h}=25 \mathrm{~cm})$ was potted in isolated PVC pottery fixed on the balcony balustrade of the residence in a height of $7 \mathrm{~m}$.

\section{Materials and procedure for epicuticular coating}

The adaxial surface of leaves attached to the plant was coated with a low viscous, translucent silicone elastomer prepolymer (Ecoflex 0030, Smooth-On Inc.) using a brush leading to a thin layer on the leaves and excess precursors were left to drop off the leaf. The coated plants were left to cure at $25^{\circ} \mathrm{C}$, $60 \% \mathrm{RH}$ for 24 hours resulting in epicuticular coatings of $\sim 10 \mathrm{mg} / \mathrm{cm}^{2}$ polymer per leaf area and a thickness of $\sim 100 \mu \mathrm{m}$.

\section{Pre- and post-coating transpiration analysis}

Whole plant transpiration analysis pre- and post-coating was performed in a transparent, gas tight chamber equipped with internal $\mathrm{CO}_{2}$ and humidity sensors (SCD30, Sensirion AG, Switzerland, sampling rate $2 \mathrm{~s}$ ) which was placed in a grow room with a 16 hours day and 8 hours night lighting cycle. External $\mathrm{CO}_{2}$ and humidity sensors (SCD30, Sensirion AG, Switzerland, sampling rate $2 \mathrm{~s}$ ) served as reference.

\section{Setup for controlled mechanical and air-flow stimulation of $c-u$ and $u-u$ leaf pairs}

To apply controlled mechanical stimuli between c-u and u-u leaf pairs, a previously described setup consisting of a linear actuator ( $4 \Omega \mathrm{HiFi}$ fullrange driver, diameter $8 \mathrm{~cm}$, model FRS, Visaton, Germany) driven by a monolithic power amplifier (OPA549T, Burr-Brown, USA) controlled by a function generator (GFG-8217A, GW Instek, Taiwan) was used applying a vertical motion selecting waveform, frequency, amplitude, and offset. ${ }^{1}$ A load cell (LRF400, FUTEK Advanced Sensor Technology, Inc., USA) was used to record the impact force during the multicycle contact-release stimuli and different impact forces were adjusted by lowering or increasing the distance between the leaf pairs during stimulation using a motorized stage in steps of $10 \mu \mathrm{m}$ (DC-3K, Controller MS 314, Märzhäuser GmbH \& Co. KG, Germany). The measurements were conducted in a Faraday cage under ambient conditions (temperature typically $22{ }^{\circ} \mathrm{C}$ and $50 \% \mathrm{RH}$ ). To simulate wind, an air flow was created by a brushless cooling fan with an outlet diameter of $4 \mathrm{~cm}$ in a distance of about $40 \mathrm{~cm}$ from the leaf pairs under investigation. Air flow was 
controlled by adjusting the fan's supply voltage and resulting wind speeds were measured using a using a hot wire anemometer (405i, Testo SE \& Co. KGaA, Germany) at a distance of $\sim 2 \mathrm{~cm}$ in front of the leaf.

\section{RF sources and controlled exposure}

During outdoor experiments, the plants were exposed to normal ambient RF radiation from, e.g., radio stations, building supplies, telecommunication etc. For in depth analysis of RF harvesting, the plants were exposed to a controllable, on/off-switchable RF source constituted by the fluorescent lighting system in the plant grow room consisting of 128 fluorescent lamps (MASTER TL5 HO 54W/840, Philips, The Netherlands) that generated a $\sim 390 \mathrm{kHz}$ center frequency RF signal received by the plants during the experiments when turned on. The generated electric field was analyzed in detail in terms of field strength and radiated power as function of distance from the source (Extended Data Fig. 5). Faraday caging made of plain square weave copper mesh with a density of 6.3 strands per cm (PSY406, Thorlabs, Germany) was used to shield RF radiation.

\section{Voltage and current measurements}

Gold coated metal pin electrodes $(0.2 \mathrm{~mm})$ were inserted into the plant tissue for electrical measurements (at the petiole for single leaves and in the stem for whole plants). Short circuit currents were measured using a high input impedance electrometer (6517B, Keithley, USA) and voltages with an oscilloscope (MSO7014A, Agilent Technologies, USA) with a passive $100 \mathrm{M} \Omega$ input impedance probe (TT-HV 150, Testec GmbH, Germany). Voltages over capacitors were recorded either by a data acquisition hardware (USB-6216, National Instruments, USA) or the electrometer (6517B, Keithley, USA). The plants were connected using coaxial cables (SMA RG142U, RS PRO, UK) to avoid interference of the cables on data acquisition.

\section{Spectrum analysis}

Spectrum analysis was performed using a spectrum and network analyzer with a frequency range from $9 \mathrm{kHz}$ to $3.2 \mathrm{GHz}$ (SVA1032X, Siglent Technologies, Germany). The plants were connected using coaxial cables (SMA RG142U, RS PRO, UK) by connecting the central pin to the pin electrode penetrating the plant tissue at the base of the stem.

\section{Electric field analysis}

Electric field strength and power was measured using a laser-powered, high-speed, low-noise 3D electric field probe operating in a frequency range from $10 \mathrm{~Hz}-8.2 \mathrm{GHz}$ (LS Probe 1.2, LUMILOOP, $\mathrm{GmbH}$, Germany).

\section{Impedance spectroscopy}

Impedance spectroscopy was performed in freshly cut branches of $H$. helix applying a $1 \mathrm{~V}$ bias between two pin electrodes inserted in the inner tissue at the indicated distances and frequencies using the precision LCR Meter (E4980A, Keysight Technologies, USA).

\section{Energy harvesting circuits, sensing and wireless data transmission}

The components for assembling the energy harvesting, sensing and data transmission circuits were low leakage diodes (BAS416, Nexperia, The Netherlands), ceramic capacitors (Taiyo Yuden Co. LTD., 
Japan) with indicated capacitances, and the temperature and humidity sensing and $868 \mathrm{MHz} \mathrm{RF}$ transmitter module (STM 330 \& HSM100, EnOcean GmbH, Germany) of which the solar cell, battery and capacitor was removed and replaced with the plants using the indicated circuits for energy harvesting, sensing, and data transmission. The plants were typically connected using coaxial cables (SMA RG142U, RS PRO, UK) by connecting the central pin to the pin electrode penetrating the plant tissue at the base of the stem.

\section{Simulation of multiple leaf energy harvesting circuit}

Circuit simulation to estimate requirements for electrical insulation between two leaves to obtain a positive power balance during energy harvesting was done in Matlab/Simulink (Version R2019b) using the circuit depicted in Fig. 1 and assuming a tissue resistance of $100 \mathrm{k} \Omega$ and a $10 \mathrm{~V}, 5 \mathrm{~Hz}$ sinusoidal alternating voltage signal generated by the leaves. The analysis of the sum signal of multiple overlapping signals randomly generated by multiple leaves was done in Matlab using a code that builds the cumulative sum of a given number of sinusoidal functions of arbitrary phase and amplitude (Extended Data Fig 2).

\section{Further instrumentation and methods}

Leaf surfaces and manually cut cross-sections of leaves with epicuticular coatings were imaged with a digital microscope (KH-8700, Hirox, USA). Transmission spectra of epicuticular coatings were measured in a UV-Vis spectrophotometer (Lambda 45, Perkin Elmer, USA). The $H$. helix support panel was cut from $5 \mathrm{~mm}$ PMMA sheets using a laser cutter (VersaLaser VLS2.30, Universal Laser Systems, Austria).

\section{Plant's mechanical energy conversion efficiency}

To estimate the efficiency to convert mechanical energy applied to a c-u leaf pair $E_{\text {mech,in }}$ into electrical energy $E_{\text {out }}$ after epicuticular coating, we analyzed the instantaneous conversion efficiency $n_{M, \text { overall }}$ of the c-u leaf contact as follows, equation (1)

$$
n_{M, \text { overall }}(\%)=\frac{E_{\text {out }}}{E_{\text {mech }, \text { in }}} 100=\frac{\int_{t_{c, \text { on }}}^{t_{c, \text { off }}} I(t)^{2} R_{L} d t}{m g h} 100
$$

where $I$ is the current produced by the c-u leaf pair, $R_{L}$ is the load resistance (10 $\mathrm{M} \Omega$ ), the potential energy $E_{\text {mech,in }}=m g h$, where $m$ is the mass of a weight (here $7 \mathrm{~g}$ ) with the dimension of $1 \mathrm{~cm}^{2}$ onto which an uncoated leaf was fixed, that was dropped from a fixed height $h(1 \mathrm{~cm})$ on to a coated leaf supported by a rigid surface, and $g$ is the gravitational acceleration. Currents across the two leaves connected through $R_{L}$ during the current peak time interval from $t_{c, \text { on }}$ to $t_{c, o f f}$ measured by an electrometer were analyzed.

\section{Analysis of capacitor charging dynamics by plant converting environmental RF energy}

To estimate the efficiency $n_{R F}$ of the plants charging the capacitor by converting RF energy at the specific given conditions, we considered the power balance between the RF input power $P_{R F, \text { in }}$ and the maximal power transfer to a load (capacitor) considering the global maximum of the instantaneous power charging the capacitor $P_{c a p, \text { charging }}=\frac{C \Delta V^{2}}{2 \Delta t}$ using the equation (2)

$$
n_{R F, \text { overall }}(\%)=\frac{P_{\text {cap, charging }}}{P_{R F, \text { in }}} 100
$$


where $C$ is the capacitance, $t$ is the time after which $V$ over the capacitor was reached, and $P_{R F, i n}=$ $\sqrt{P_{x}^{2}+P_{y}^{2}+P_{z}^{2}}$ where $P_{x}, P_{y}, P_{z}$ are the $\mathrm{x}-, \mathrm{y}-$, and $\mathrm{z}$-components of the electric field power averaged over the full plant height in z direction, measured in the vicinity of the plant by an electric field probe.

The short circuit current related to capacitor charging was calculated by equation (3) for $t \rightarrow 0$ and capacitor initially discharged.

$$
I_{S C, \text { cap }}=\lim _{t \rightarrow 0} C \frac{d V}{d t} ; V_{(0)}=0
$$

and the load equivalent was estimated by equation (4)

$$
R_{e}=\frac{\Delta V}{\Delta I}
$$

To determine the load at which the maximal instantaneous power $P_{\text {cap,charging }}$ was transferred.

To estimate the conversion efficiency of the RF harvesting circuit $n_{\text {circuit }}$ under the specific conditions of the experiment, the power balance between and the maximal power transfer to the load (capacitor) considering the global maximum of the instantaneous power charging the capacitor $P_{\text {cap,charging }}$ and the power received by the plant, $P_{S A}$, was considered, equation (5)

$$
n_{\text {circuit }}(\%)=\frac{P_{\text {cap, charging }}}{P_{S A}} 100
$$

Here, $P_{S A}$ is the average power of RF signals received by the plant with RF source turned on. The power of RF signals received by plant was measured by the spectrum analyzer.

\section{Analysis of increase of energy harvested by plant multimodal energy harvesting}

A factor $f_{E \text {,increase }}$ representing the energy rise by multimodal (RF + mechanical/wind) energy harvesting compared to single mode harvesting was calculated by (6):

$$
f_{E, \text { increase }}=\frac{\Delta E_{\text {multimode }}}{\Delta E_{\text {single mode }}}=\frac{\frac{1}{2} C \Delta V_{W R F}^{2}}{\frac{1}{2} C \Delta V_{S}^{2}}
$$

where $V_{W, R F}$ is the voltage over capacitor harvested by wind and RF stimuli and $V_{S}$ is the voltage over the capacitor when a single energy source (RF or mechanical) is converted by the plant into electrical energy. The variation of $E_{\text {single mode }}$ and $E_{\text {multimode }}$ during 10 min capacitor charging (in intervals of $30 \mathrm{~ms}$ ) have been considered.

\section{Charges required for sensing and wireless transmission cycle}

In order to estimate the charges required for a measurement cycle $Q_{\text {meas }}$ (charge required for sensing the humidity and temperature and wirelessly transmitting the data to the receiver), the variation in the voltage $V_{\text {cap,senor }}$ across the capacitor with capacitance $C$ during a measurement cycle was analyzed in the corresponding time interval using equation (7):

$$
Q_{\text {meas }}=C\left(V\left(t_{1}\right)-V\left(t_{2}\right)\right)
$$

Where $t_{1}$ and $t_{2}$ are the timepoints of begin and end of the measurement cycle, respectively. 
422 Averages and standard deviations of typically five measurements are reported. Analysis with controlled mechanical stimulation are averages and standard deviations of forty to sixty tests per condition. The data was analyzed in Matlab (Version 2019b).

Data availability

The data supporting the findings of this study are available from the corresponding authors on reasonable request. (additional publication in an online repository before publication planned).

\section{Acknowledgements}

This work was funded by the project GrowBot, the European Union's Horizon 2020 Research and Innovation Programme under Grant Agreement No. 824074.

431

432

433

434

435

436

437

\section{Author contributions}

F.M. conceived and developed the idea, performed the experiments, and wrote the manuscript. F.M., A.M., and B.M. designed experiments. F.M., A.M., F. V., G.Z., and M.C. analyzed the data and wrote the manuscript. F.M. wrote the manuscript with contributions of all authors. All authors contributed equally in revising the manuscript.

\section{Extended Data}
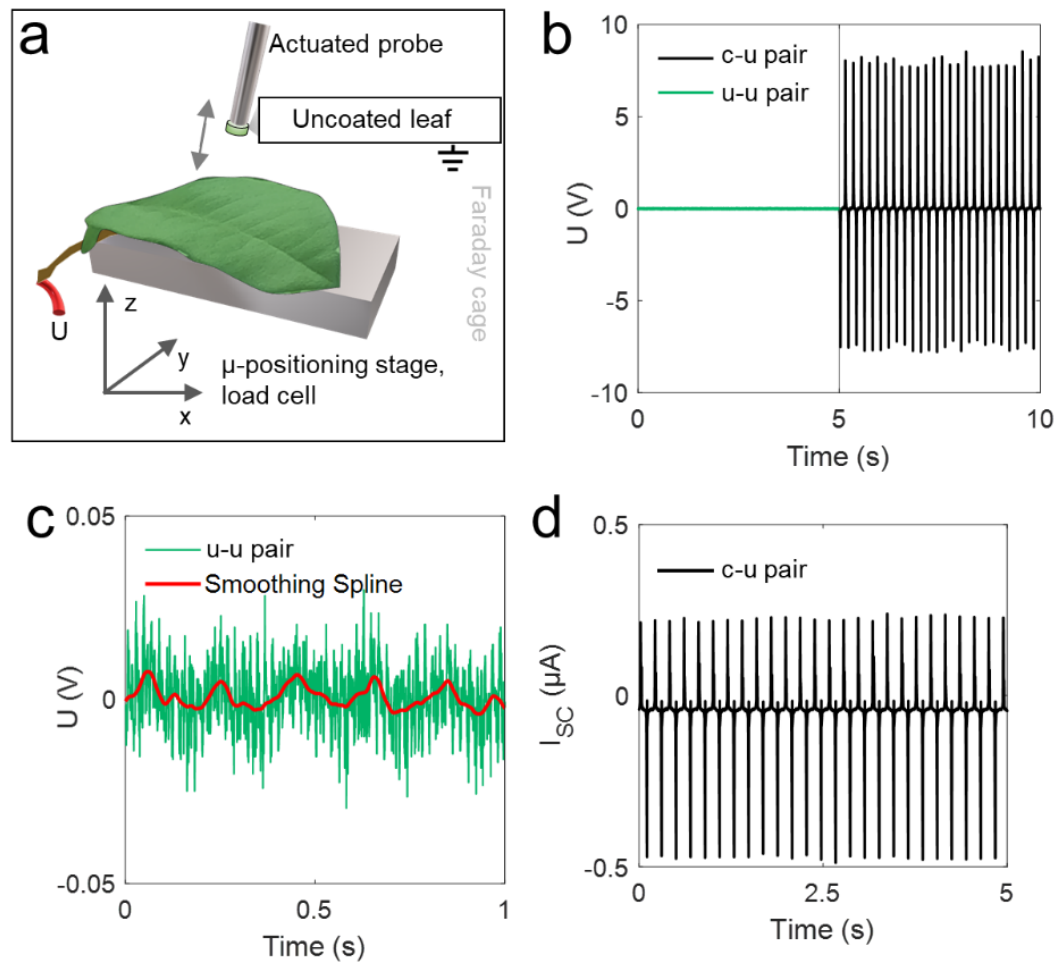

Extended Data Fig 1. Mechanical energy conversion by c-u leaf pairs. a) Schematic of the setup for applying controlled mechanical stimuli on a leaf using a circular section of an uncoated leaf to establish $\mathrm{u}-\mathrm{u}$ and c-u pairs. b) Alternating voltage signals generated by a c-u F. microcarpa pair @ $5 \mathrm{~Hz}, 1 \mathrm{~N}$ 
stimulus showing significant enhancement of the c-u pair after epicuticular coating. c) Zoom-in of the voltage signal generated by the u-u pair with an amplitude of $\sim 45 \mathrm{mV}$. The smoothing spline reveals the $5 \mathrm{~Hz}$ stimulus signal. The amplitude of the c-u pair is thus $\sim 450$ times higher as achieved by the $\mathrm{u}-$ u pair. d) Short circuit current generated by a c-u F. microcarpa pair @ $5 \mathrm{~Hz}, 1 \mathrm{~N}$ stimulus.

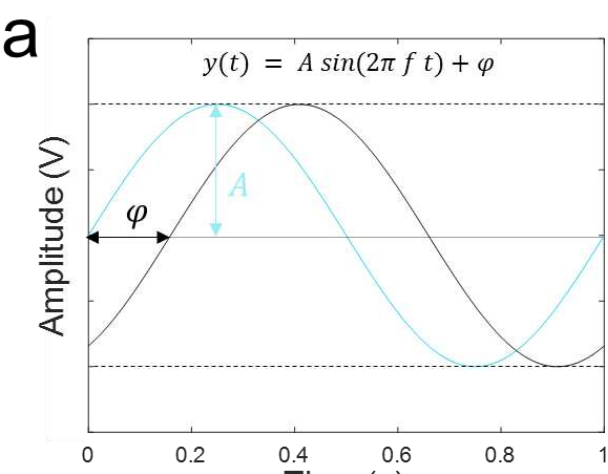

b
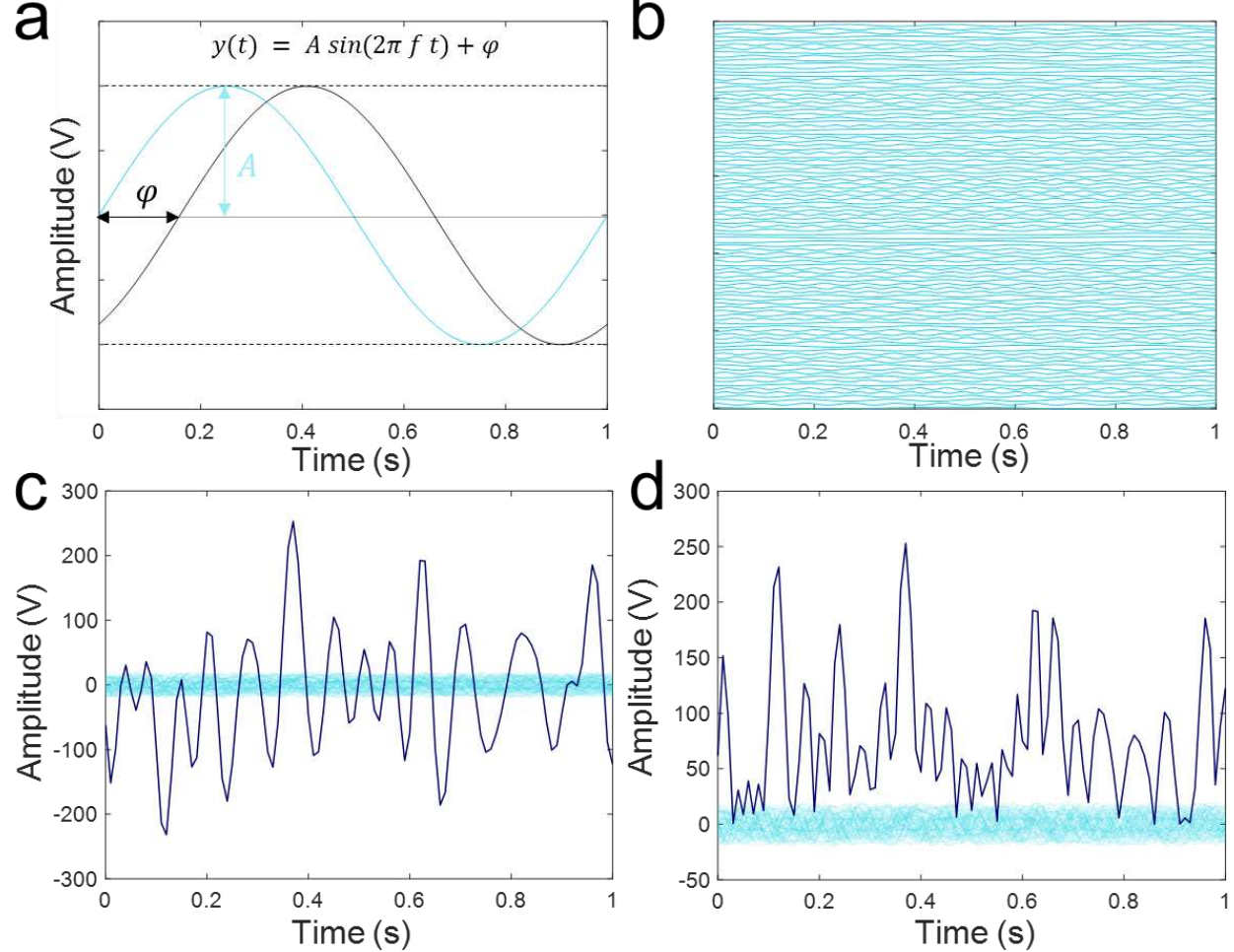

Extended Data Fig 2. Analysis of the sum signal of multiple alternating sinusoidal signals representative for a scenario in which multiple leaves simultaneously convert mechanical contacts into electricity. a) and b) 100 sinusoidal signals with random amplitude $A$, frequency $f$, and phase shift $\varphi$ (in the limits of $A=1$ to $10 \mathrm{~V}, f=1$ to $20 \mathrm{~Hz}$, and $\varphi=0$ to $0.05 \pi$, respectively) were generated. c) and d) show the direct and "rectified" sum signal (dark blue curves), respectively of the 100 input curves (light blue) indicating that the overlapping signals from multiple leaves may sum up leading to 

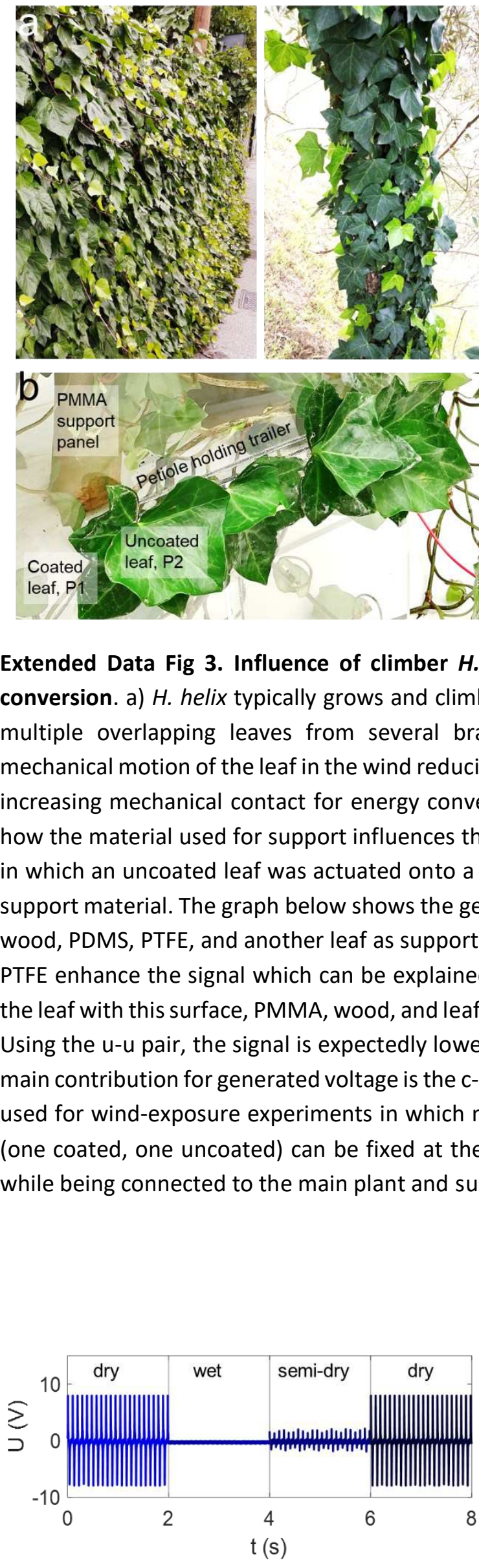
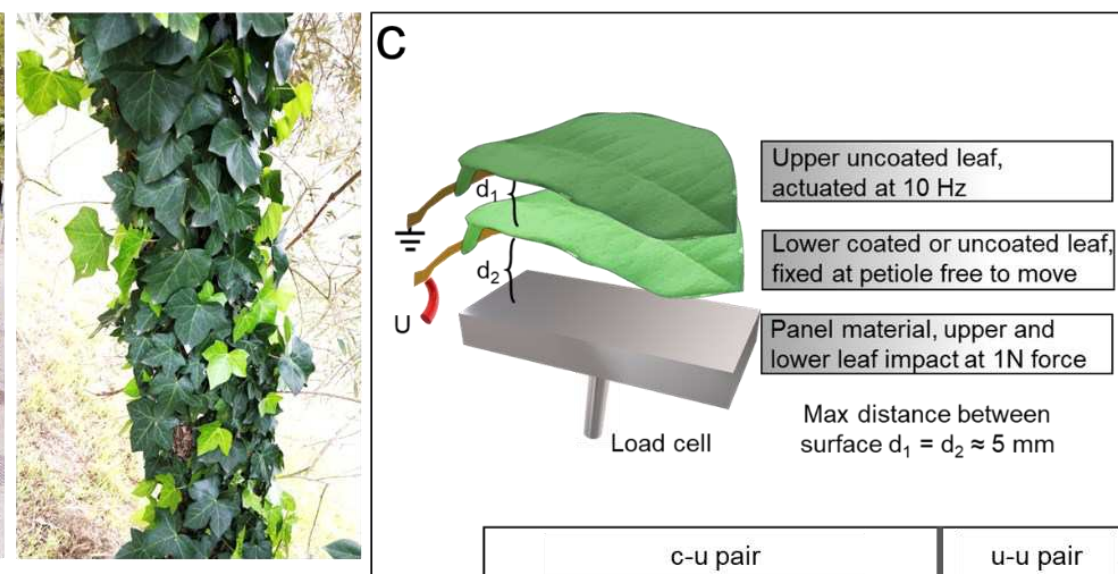

actuated at $10 \mathrm{~Hz}$

Lower coated or uncoated leaf, fixed at petiole free to move
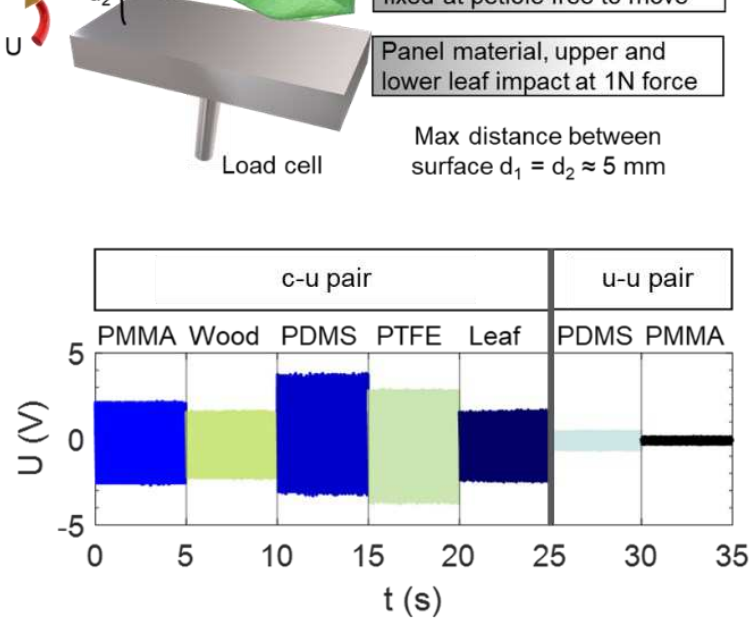

Extended Data Fig 3. Influence of climber $\boldsymbol{H}$. helix' support material on the mechanical energy conversion. a) $H$. helix typically grows and climbs on a rigid support such as a wall or tree leading to multiple overlapping leaves from several branches. The support also introduces a barrier for mechanical motion of the leaf in the wind reducing the degrees of freedom for elastic deformation and increasing mechanical contact for energy conversion between the overlapping leaves. b) We tested how the material used for support influences the voltage generation using the depicted arrangement in which an uncoated leaf was actuated onto a coated/uncoated leaf kept at a given distance from a support material. The graph below shows the generated voltage signals ( $10 \mathrm{~Hz}$ stimulus) using PMMA, wood, PDMS, PTFE, and another leaf as support material when analyzing $\mathrm{c}-\mathrm{u}$ and $\mathrm{u}$-u pairs. PDMS and PTFE enhance the signal which can be explained by an additional contact charging due to contact of the leaf with this surface, PMMA, wood, and leaf as a substrate does not significantly change the signal. Using the u-u pair, the signal is expectedly lower and only slightly increased by the substrate and the main contribution for generated voltage is the $\mathrm{c}-\mathrm{u}$ and $\mathrm{u}$-u leaf pair. $\mathrm{c}$ ) Depicts the PMMA support panel used for wind-exposure experiments in which multiple leaves of two branches of two $\mathrm{H}$. helix plants (one coated, one uncoated) can be fixed at the petiole creating a c-u pair free to move in the wind while being connected to the main plant and supported by the PMMA panel.

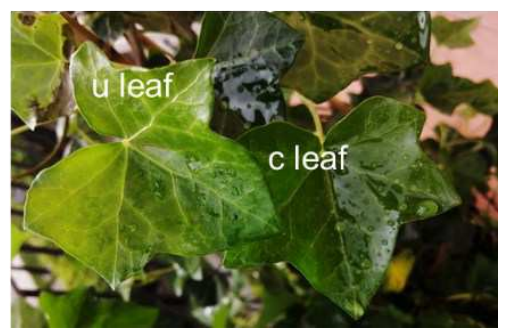


Extended Data Fig 4. Influence of leaf-wetting on c-u leaf pair energy conversion. A H. helix c-u leaf pair was exposed to a $10 \mathrm{~Hz}$ mechanical stimulus and voltage amplitude is recorded before and after wetting by water spraying. Wetting expectedly strongly reduces contact electrification and obtained voltage amplitudes. However, the signal recovers when the leaves dry again.
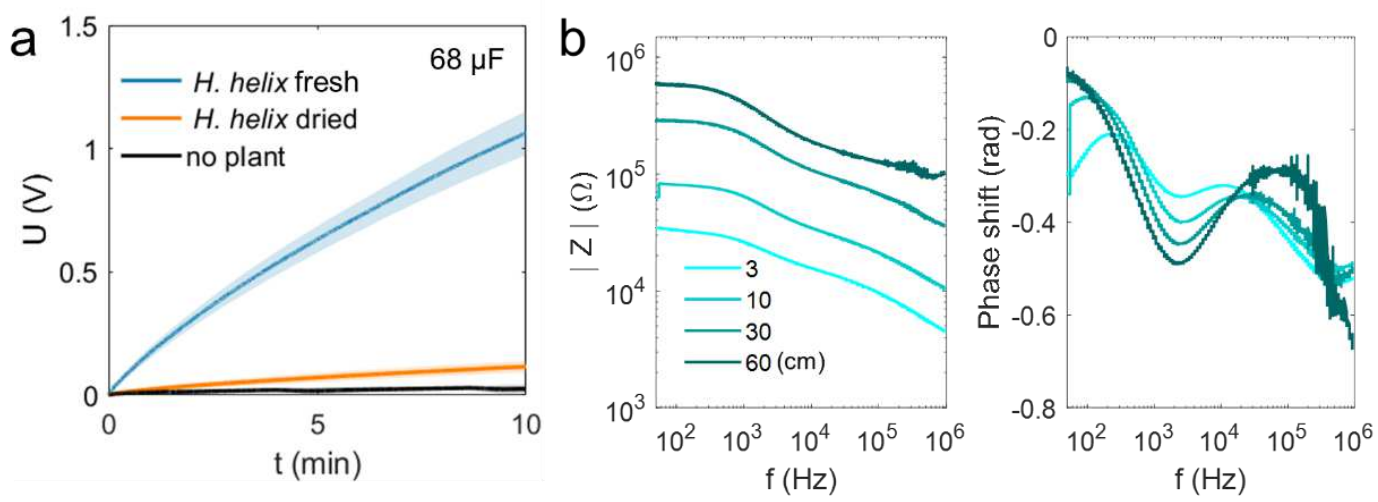

Extended Data Fig 5. Effect of ion conduction obstruction by tissue drying on energy harvesting and impedance analysis. a) Influence of the $H$. helix water content on RF energy conversion and capacitor charging. Naturally drying the tissue (by omitting watering for 4 weeks, orange curve) obstructs ion conduction and results in an almost complete loss of charging compared to the fresh $\mathrm{H}$. helix (blue curve) indicating that tissue water content and related ion mobility in living plants is expectedly essential for RF energy conversion and harvesting. b) Bode plots of impedance $|Z|$ and phase shift of a $H$. helix branch (diameter $\sim 5 \mathrm{~mm}$ ) as function of the length given in $\mathrm{cm}$.
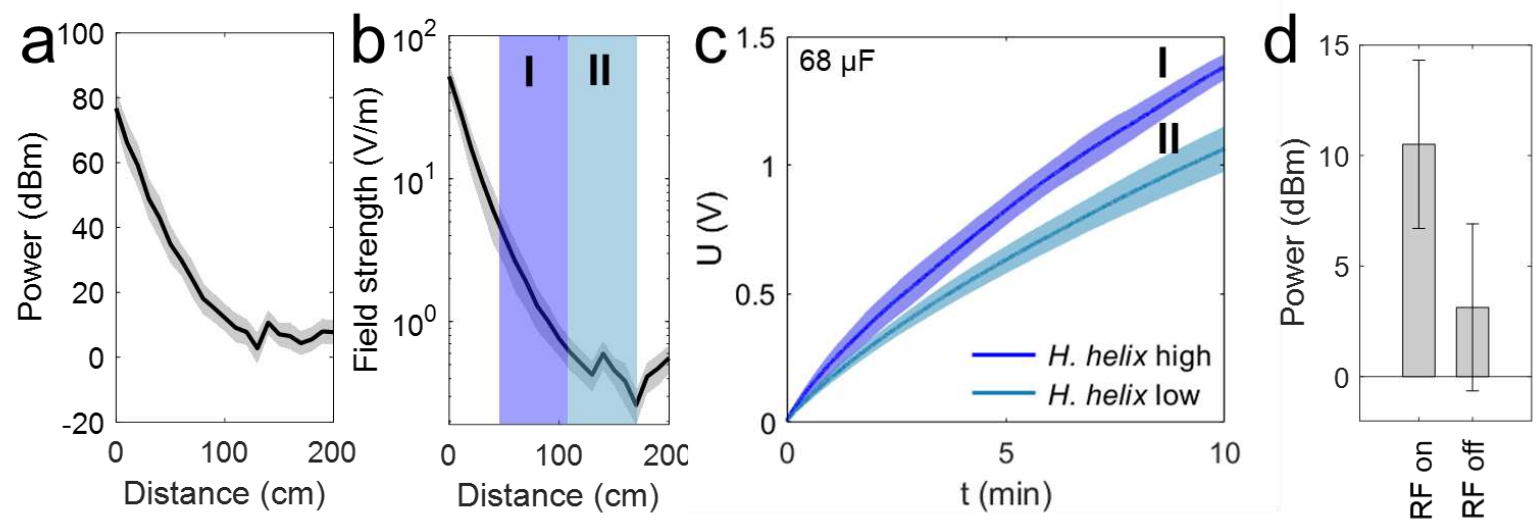

Extended Data Fig 6. Electric field characteristics and field strength-dependent energy harvesting using $\boldsymbol{H}$. helix. a) and b) power and field strength as function of distance of RF source. c) $68 \mu \mathrm{F}$ capacitor charging with $H$. helix when placed in different distances from the RF source corresponding to the blue (I.) and green (II.) area in b). d) Difference in the average power of the electric field measured when RF source (fluorescent lighting system) is switched on/off. 

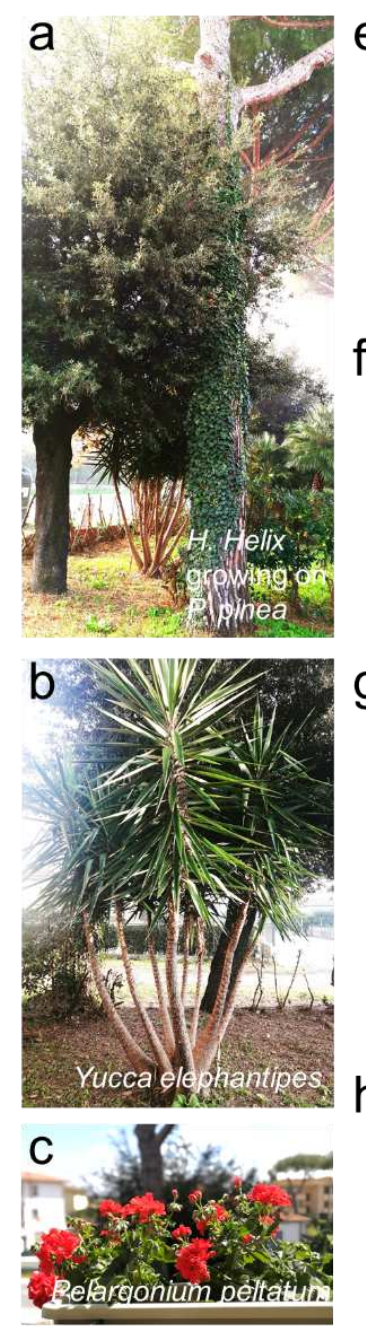
building mains.

\section{References}
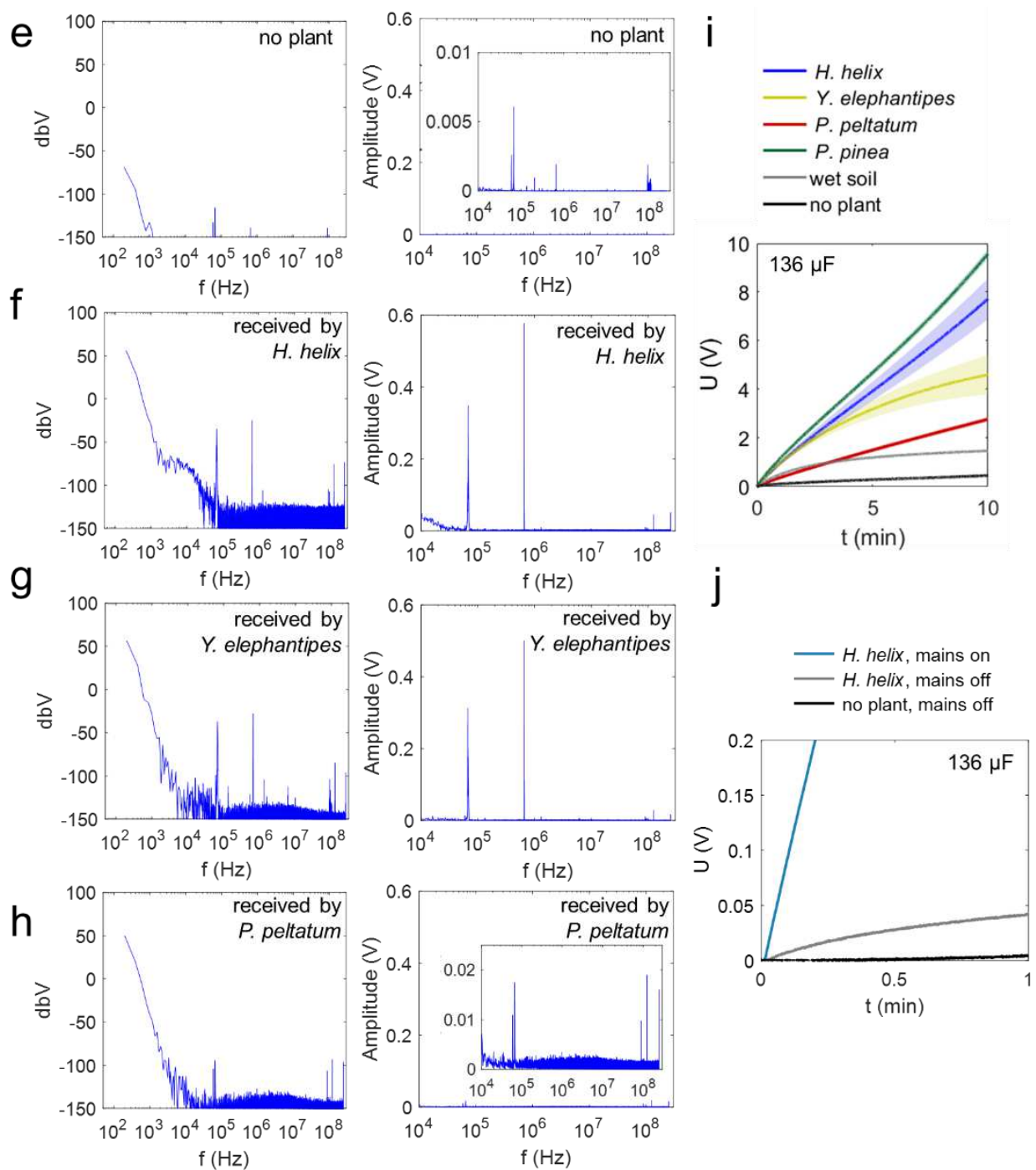

Extended Data Fig 7. Application scenario: Signals received during plant-based RF energy harvesting in an urban outdoor environment. a) to c) images of the different species used for energy harvesting in a front garden and on a balcony of a multifamily residence. e) to $h$ ) Hanning-windowed frequency spectrum analysis ( $\mathrm{dbV}$, full range, left; $\mathrm{V},>10 \mathrm{kHz}$, right) of voltage signals received by different plants (H. helix, Y. elephantipes, and P. peltatum). The house' ground was used as reference point/potential difference. Insets are zoom-ins into smaller peaks of the spectrum. Plants strongly increase signal reception at multiple frequencies starting from super low mains noise. Spectrum analysis of $H$. helix and $Y$. elephantipes shows among other frequencies also signals related to a nearby $657 \mathrm{kHz} \mathrm{MW}$ radio emitter (8 km distance). i) Plant-dependent charging dynamics of a $136 \mu \mathrm{F}$ capacitor. Wet soil (electrode inserted $20 \mathrm{~cm}$ ) and no plant, respectively are plotted as reference. P. pinea results in highest instantaneously transferred power of $\sim 10 \mu \mathrm{W}$ and $H$. helix in $6.8 \mu \mathrm{W}$, P. peltatum in $0.8 \mu \mathrm{W}$ showing a plant-dependent behavior likely due to plant size and branching that forms the receiving antenna. j) Analysis of $136 \mu \mathrm{F}$ capacitor charging dynamics by $H$. helix when the mains circuit of the near-by multifamily residence is turned off, revealing that the energy output is strongly affected by the 
1. Meder, F. et al. Energy Conversion at the Cuticle of Living Plants. Adv. Funct. Mater. 28, 1806689 (2018).

2. Jie, Y. et al. Natural Leaf Made Triboelectric Nanogenerator for Harvesting Environmental Mechanical Energy. Adv. Energy Mater. 8, 1703133 (2018).

3. Kim, D. W., Kim, S. \& Jeong, U. Lipids: Source of Static Electricity of Regenerative Natural Substances and Nondestructive Energy Harvesting. Adv. Mater. 30, 1804949 (2018).

4. Wu, H. et al. Fully Biodegradable Water Droplet Energy Harvester Based on Leaves of Living

5. Meder, F., Thielen, M., Mondini, A., Speck, T. \& Mazzolai, B. Living Plant-Hybrid Generators for

6. Lew, T. T. S., Koman, V. B., Gordiichuk, P., Park, M. \& Strano, M. S. The Emergence of Plant

7. Wong, M. H. et al. Nitroaromatic detection and infrared communication from wild-type plants

8. Kim, J. J., Allison, L. K. \& Andrew, T. L. Vapor-printed polymer electrodes for long-term, onusing plant nanobionics. Nat. Mater. 16, 264-272 (2017).

9. Giraldo, J. P. et al. Plant nanobionics approach to augment photosynthesis and biochemical sensing. Nat. Mater. 13, 400-408 (2014).

10. Kim, J. J., Fan, R., Allison, L. K. \& Andrew, T. L. On-site identification of ozone damage in

11. Lew, T. T. S., Park, M., Cui, J. \& Strano, M. S. Plant Nanobionic Sensors for Arsenic Detection. fruiting plants using vapor-deposited conducting polymer tattoos. Sci. Adv. 6, 1-10 (2020). Adv. Mater. 33, 1-11 (2021).

12. Jiang, J., Zhang, S., Wang, B., Ding, H. \& Wu, Z. Hydroprinted Liquid-Alloy-Based Morphing Electronics for Fast-Growing/Tender Plants: From Physiology Monitoring to Habit Manipulation. Small 16, (2020).

13. Shogren, R., Wood, D., Orts, W. \& Glenn, G. Plant-based materials and transitioning to a circular economy. Sustain. Prod. Consum. 19, 194-215 (2019).

14. Stavrinidou, E. et al. In vivo polymerization and manufacturing of wires and supercapacitors in plants. Proc. Natl. Acad. Sci. 114, 2807-2812 (2017).

15. Stavrinidou, E. et al. Electronic plants. Sci. Adv. 1, e1501136-e1501136 (2015).

16. Li, W. et al. An on-demand plant-based actuator created using conformable electrodes. Nat.

17. Deng, H., Chen, Z. \& Zhao, F. Energy from Plants and Microorganisms : Progress in Plant -

18. Strik, D. P. B. T. B., Bert, H. V. M. H., Snel, J. F. H. \& Buisman, C. J. N. Green electricity production with living plants and bacteria in a fuel cell. Int. J. ENERGY Res. 32, 870-876 (2008).

19. Flexer, V. \& Mano, N. From dynamic measurements of photosynthesis in a livir
sunlight transformation into electricity. Anal. Chem. 82, 1444-1449 (2010). 
20. Miyake, T. et al. Enzymatic biofuel cells designed for direct power generation from biofluids in living organisms. Energy Environ. Sci. 4, 5008-5012 (2011).

21. Lowell, J. \& Rose-Innes, A. C. Contact electrification. Adv. Phys. 296, 947-1023 (1980).

22. Lin, Z. \& Chi, A. On the origin of contact-electrification. Mater. Today 30, 34-51 (2019).

23. Lacks, D. J. \& Shinbrot, T. Long-standing and unresolved issues in triboelectric charging. Nat. Rev. Chem. 3, 465-476 (2019).

24. Yeats, T. H. \& Rose, J. K. C. The Formation and Function of Plant Cuticles. Plant Physiol. 163, 520 (2013).

25. Köhler, M. Green facades-a view back and some visions. Urban Ecosyst. 11, 423-436 (2008).

26. Bai, Y., Jantunen, H. \& Juuti, J. Energy harvesting research: The road from single source to multisource. Adv. Mater. 30, 1-41 (2018).

27. Thainiramit, P., Yingyong, P. \& Isarakorn, D. Impact-driven energy harvesting: Piezoelectric versus triboelectric energy harvesters. Sensors 20, 1-20 (2020).

28. Bai, Y., Jantunen, H. \& Juuti, J. Hybrid, multi-source, and integrated energy harvesters. Front. Mater. 5, 1-10 (2018).

29. Ikrath, K., Kennebeck, W. \& Hoverter, R. T. Trees Performing as Radio Antennas. IEEE Trans. Antennas Propag. 23, 137-140 (1975).

30. Skrivseth, K. Signal Propagation at $400 \mathrm{kHz}$ Using an Oak Tree with a HEMAC as an Antenna. US Army Electronics Command (171AD).

31. Schmidt, G. \& Berta, I. Radiated Radiofrequency Emission from the Plasma of Compact Fluorescent Lamps. Int. J. Plasma Environ. Sci. Technol. 5, 84-92 (2011).

32. Hua, C., Shen, Z. \& Lu, J. High-efficiency sea-water monopole antenna for maritime wireless communications. IEEE Trans. Antennas Propag. 62, 5968-5973 (2014).

33. Cansiz, M., Altinel, D. \& Kurt, G. K. Efficiency in RF energy harvesting systems: A comprehensive review. Energy 174, 292-309 (2019). 


\section{Figures}
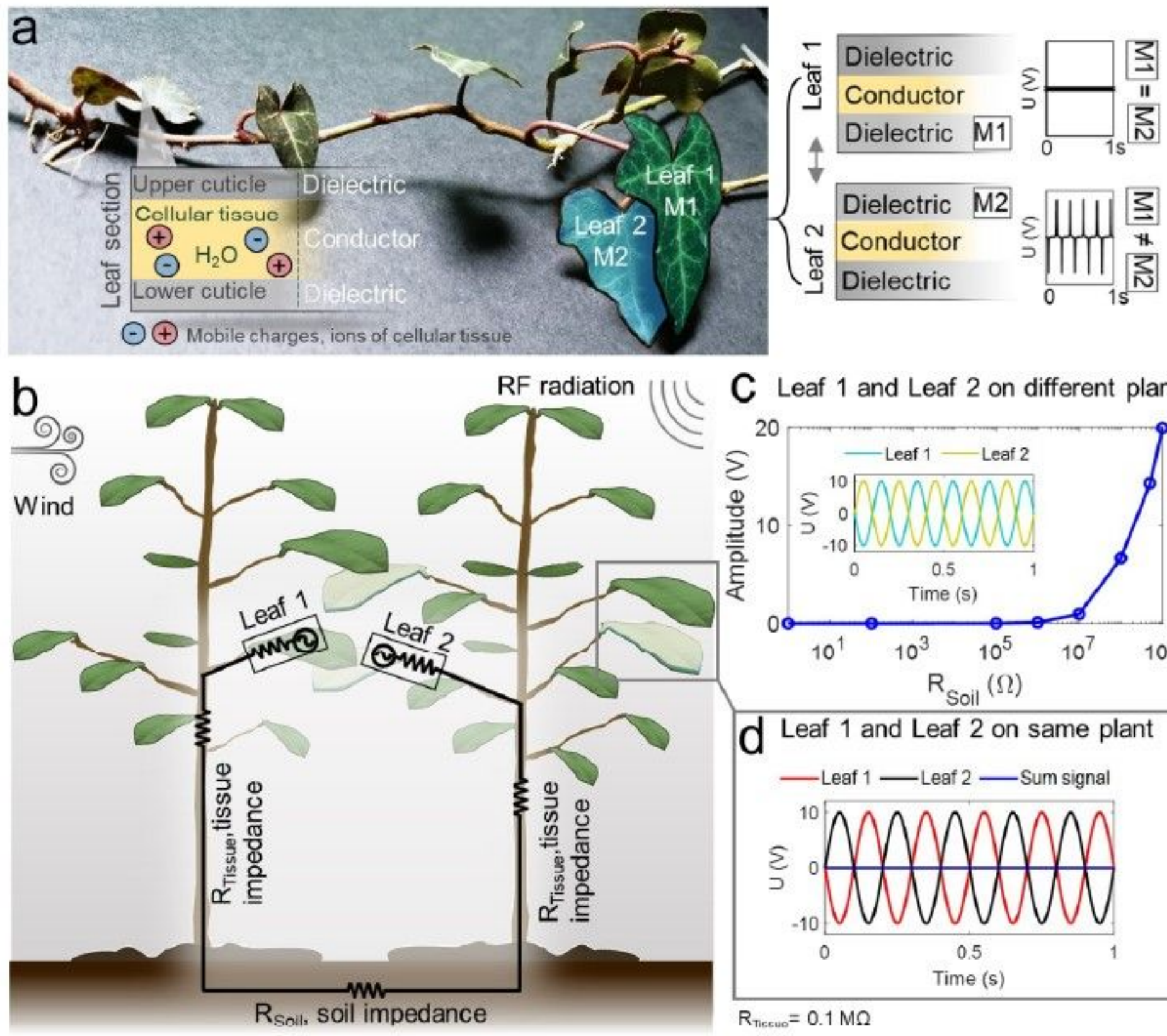

C Leaf 1 and Leaf 2 on different plant

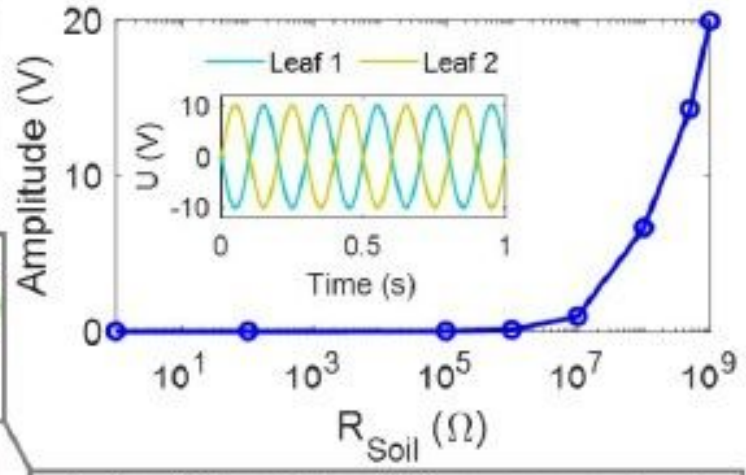

d Leaf 1 and Leaf 2 on same plant

—Legf 1 - Leaf 2 - Sum signal

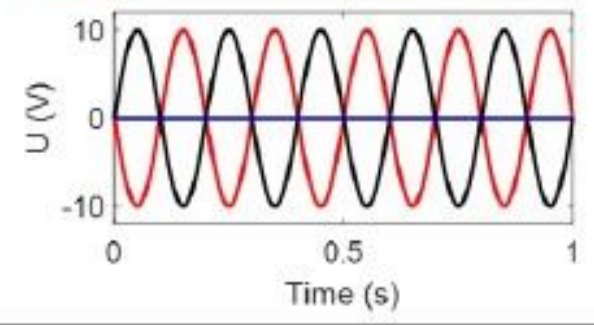

$R_{\text {Teceuo }}=0.1 \mathrm{M} \Omega$

\section{Figure 1}

Overview and model of living plant structure-based multisource energy harvesting. a) Inner cellular and vascular tissue are ionic conductors; the cuticle on the plant surface is a dielectric polymeric layer. When a leaf with epicuticular coating comes in contact with an uncoated leaf, contact electrification generates only considerable voltages $\mathrm{U}$ in the tissue if the dielectric material $\mathrm{M} 1$ and $\mathrm{M} 2$ inhere a material pair that specifically enhances contact electrification, typically $M 1 \neq M 2$. b) Illustration of basic circuitry established by the plants in a wind and RF energy harvesting scenario. c) Circuit modelling reveals that during mechanical interaction of two leaves from different plants, voltages in the tissue build up only when Rsoil 
is sufficiently high. d) Signals of the two leaves cancel out when the leaves are on the same plant, due to too low tissue impedances (typically 0.1-1 MS).

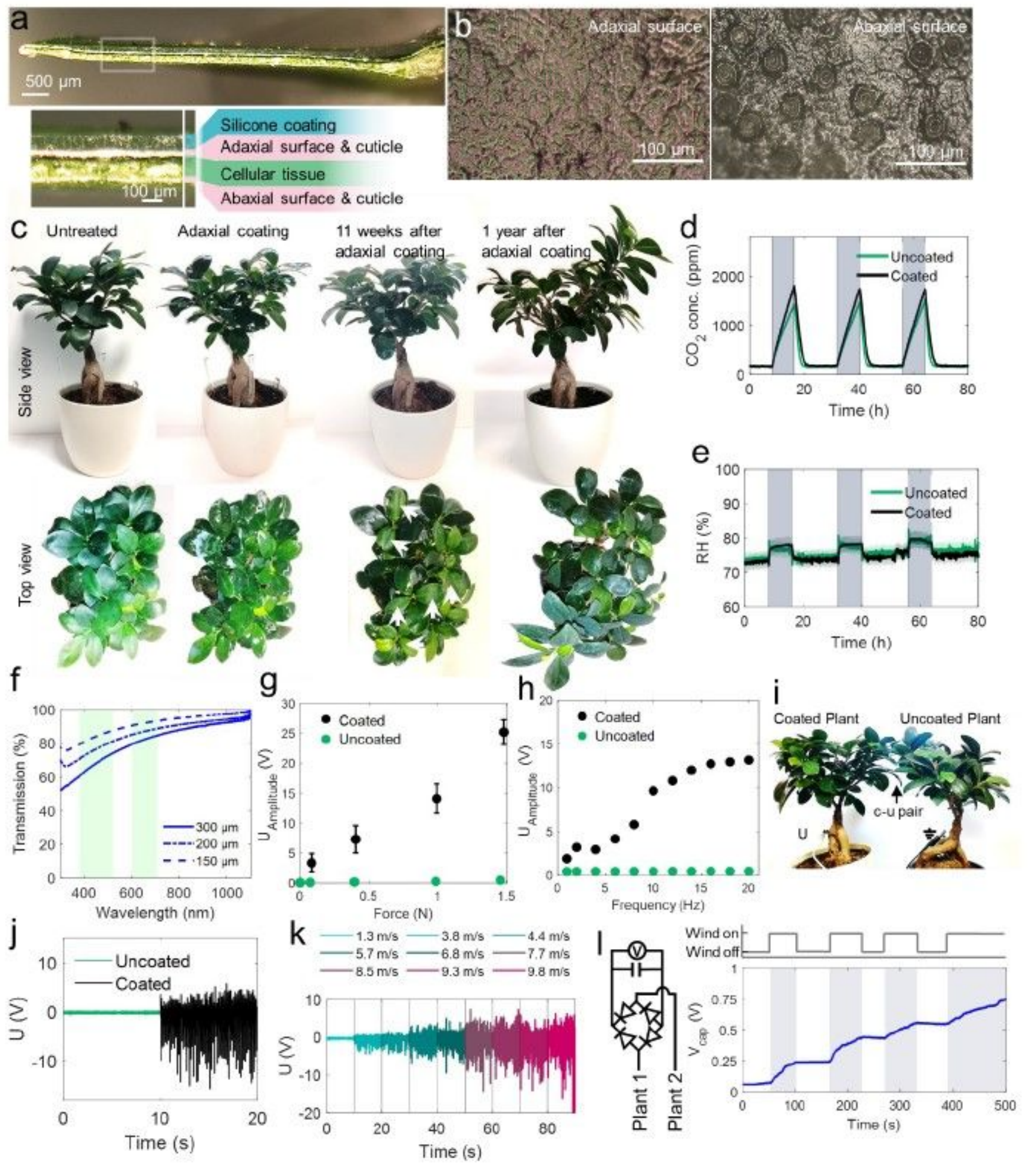

Figure 2

Leaf-epiculticular coating, influence on plant viability, and enhancement of mechanical energy harvesting. a) Cross-section of F. microcarpa leaf with $\sim 100 \mu \mathrm{m}$ epicuticular silicone rubber coating on adaxial surface. b) Microscopy images representing stomatal density on adaxial and abaxial leaf surface. c) One- 
year growth observation of a fully coated F. microcarpa. White arrows point to new leaves that developed within 11 weeks after coating growing further into new branches within 1 year. d) and e) $\mathrm{CO} 2$ and $\mathrm{H} 2 \mathrm{O}$ transpiration (in $\mathrm{RH} \%$ ), respectively before and after epicuticular coating. f) Light transmission of epicuticular coatings, green bars highlight photosynthesis relevant wavelengths. g) and h) Enhancement of voltage generation after epicuticular coating as function of impact force (@10 Hz frequency), and of frequency (@1N impact force), respectively in u-u and c-u leaf pairs. i) Two F. microcarpa (left, coated, right uncoated) in separate pots, overlapping leaves used for wind energy harvesting. j) Air-flow induced voltage generation of the $u-u$ and c-u F. microcarpa pair. k) Voltage generation as function of windspeed in a c-u F. microcarpa pair. I) c-u F. microcarpa leaf pair-based capacitor charging $(10 \mu \mathrm{F})$ with indicated circuit as function of wind source on-off switching.
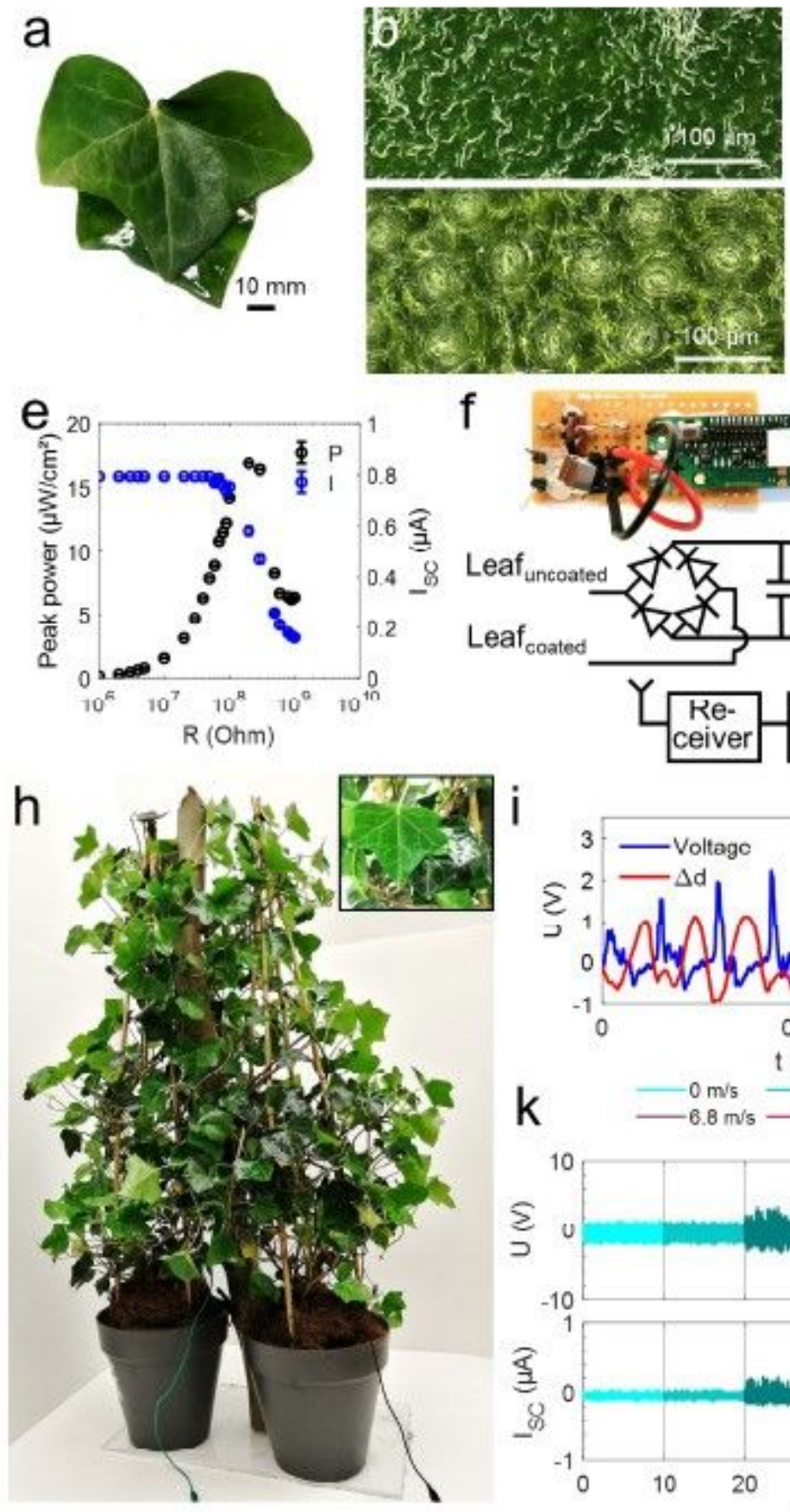
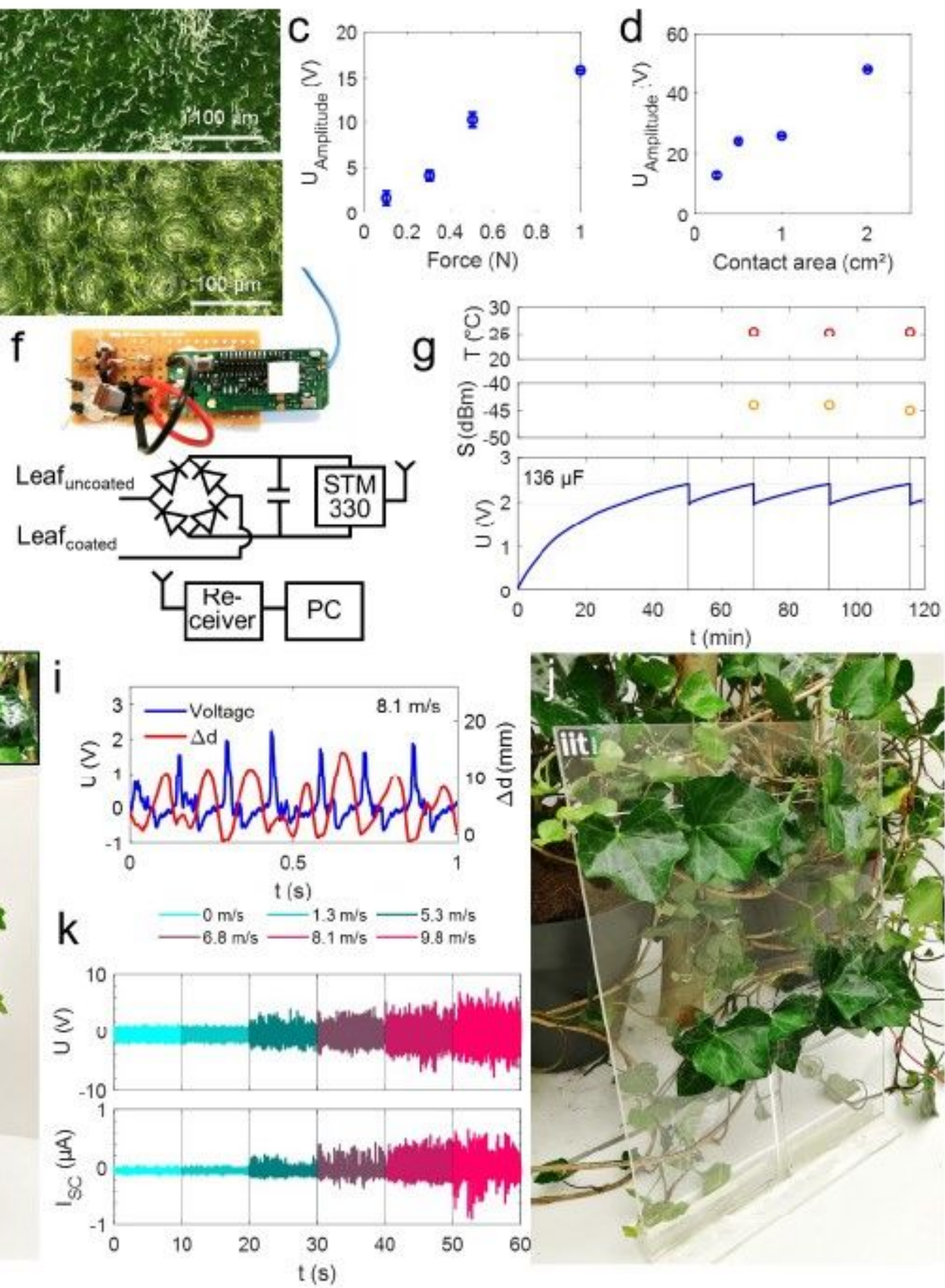


\section{Figure 3}

Realization of mechanical energy harvesting in epicuticular coated climber H. helix. a) Photograph of a H. helix c-u leaf pair. b) Microscopy images representing stomatal density adaxial on adaxial and abaxial leaf surface. c) and d) Voltage amplitude generated by a H. helix c-u leaf pair as function of impact force (@ contact area $0.25 \mathrm{~cm}^{2}$ ) and contact area (@1 $\mathrm{N}$ impact force), respectively (10 Hz stimulus).e) H. helix c-u leaf pair peak power analysis as function of load of resistance. f) Circuit overview used in g) wirelessly transmitted temperature measurement data packets and signal strength of a c-u leaf pair powered wireless sensor (@1 N, $30 \mathrm{~Hz}$ mechanical stimulation). h) Typical arrangement for $\mathrm{H}$. helix wind energy harvesting in which multiple c-u leaf pairs are realized from two separately potted plants. i) Correlation of voltage signal generated and distance of the two surfaces in a H. helix c-u leaf pair fluttering in air-flow. j) Voltage and short circuit current generated by eight c-u pairs under wind excitation. Unidirectional leaf pairs were realized by fixing two branches of the two $\mathrm{H}$. helix on a support panel as shown in k) for exposure to wind. 

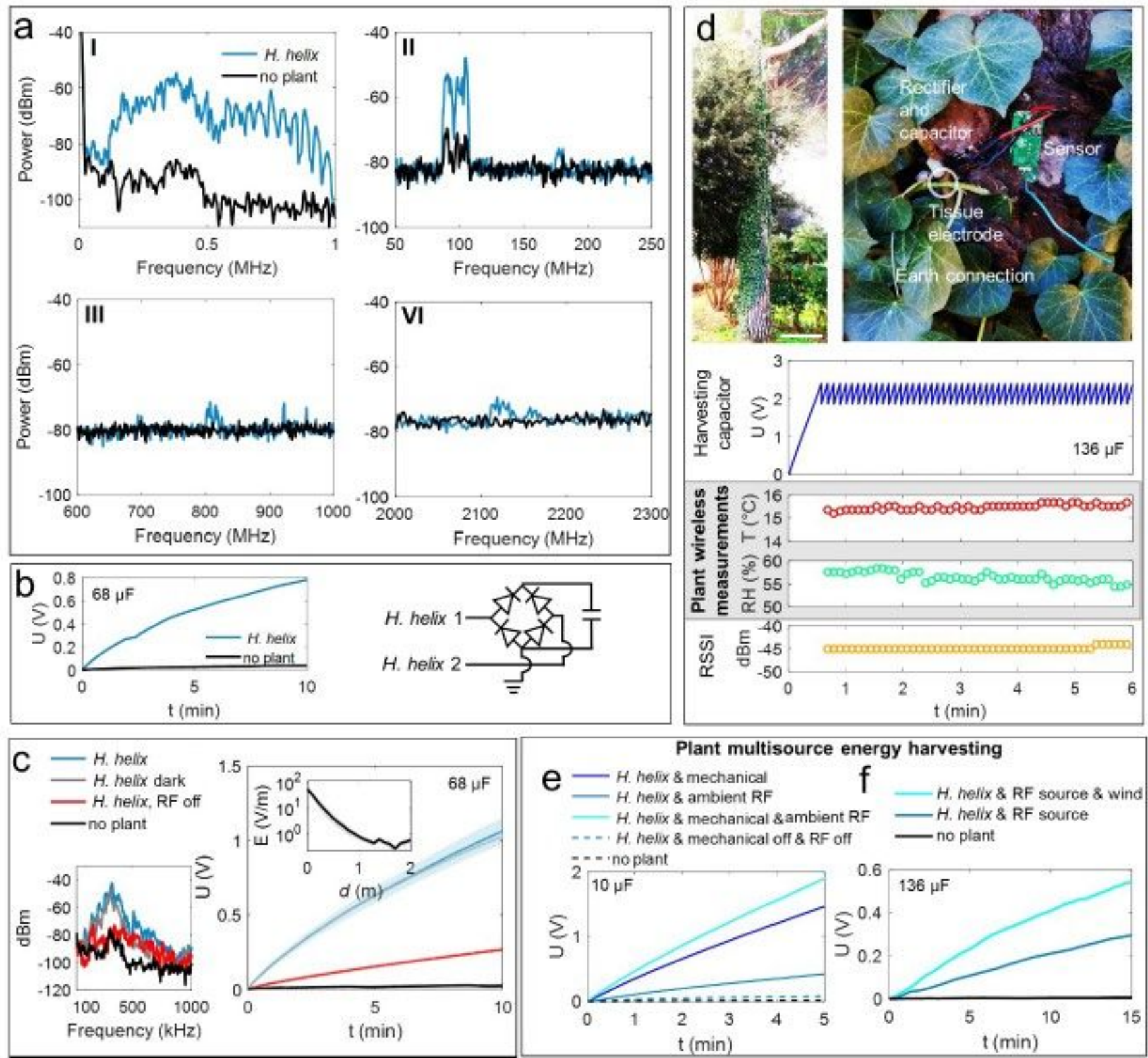

\section{Figure 4}

Plant based RF energy harvesting and boosted multisource wind-RF energy harvesting. a) and b) overview of the frequencies received by an H. helix acting as antenna outdoor (e.g., @100 MHz, center frequency of nearby radio emitter), circuit and charging curve of a $68 \mu \mathrm{F}$ capacitor relative to these signals, respectively indicating potential to transduce RF radiation into electricity. c) Exposure of $\mathrm{H}$. helix in dark and light conditions to a switchable RF source resulting in a received main frequency $\sim 400 \mathrm{kHz}-$ center when the RF source is on, when off, the peak diminishes. The capacitor charging curves $(68 \mu \mathrm{F})$ show RF-source and plant-dependent energy harvesting by $\mathrm{H}$. helix. The inset shows the electric field strength as function of distance from the RF source, energy harvesting was performed in 1 $\mathrm{m}$ distance, further details in Extended Data Fig. 5. d). Demo of a plant-powered sensing and wireless data packet transmission using a modified commercial sensing system in an outdoor environment with a $\mathrm{H}$. helix growing on a pine tree, charging of a $136 \mu \mathrm{F}$ capacitor powering sensor and transceiver unit. The plant 
powers a humidity/temperature sensor and wireless data transmission, plant-powered measurements and transmission signal strengths are given. e) Multisource (mechanical and RF) energy harvesting with a c-u H. helix pair by selectively adding RF (environmental) or mechanical energy (controlled $1 \mathrm{~N}, 10 \mathrm{~Hz}$ stimulus) sources leads to increasing capacitor charging dynamics. f) Multisource wind and RF plant energy harvesting, wind speed $\sim 8.1 \mathrm{~m} / \mathrm{s}, \mathrm{RF}, 400 \mathrm{kHz}$ center frequency, (see spectrum analysis in $\mathrm{c}$ )), conversion by $\mathrm{c}-\mathrm{u} \mathrm{H}$. helix pairs as described in Fig. 3 feeding a $136 \mu \mathrm{F}$ capacitor. Combination of RF and wind leads to a $550 \%$-increase in the energy output compared to RF as single source.

\section{Supplementary Files}

This is a list of supplementary files associated with this preprint. Click to download.

- Video1.mp4 